Article

\title{
Freeze-Thaw Deformation Cycles and Temporal-Spatial Distribution of Permafrost along the Qinghai-Tibet Railway Using Multitrack InSAR Processing
}

\author{
Jing Wang ${ }^{1,2,3}$, Chao Wang ${ }^{1,2,3, * \mathbb{C}}$, Hong Zhang ${ }^{1,2,3}$, , Yixian Tang ${ }^{1,2,3}$, Wei Duan ${ }^{1,2,3}$ and Longkai Dong ${ }^{1,2,3}$ \\ 1 Key Laboratory of Digital Earth Science, Aerospace Information Research Institute, Chinese Academy of \\ Sciences, Beijing 100094, China; wangjing2018@radi.ac.cn (J.W.); zhanghong@radi.ac.cn (H.Z.); \\ tangyx@aircas.ac.cn (Y.T.); duanwei15@mails.ucas.ac.cn (W.D.); donglk@aircas.ac.cn (L.D.) \\ 2 International Research Center of Big Data for Sustainable Development Goals, Beijing 100094, China \\ 3 College of Resources and Environment, University of Chinese Academy of Sciences, Beijing 100049, China \\ * Correspondence: wangchao@radi.ac.cn; Tel.: +86-10-821-781-61
}

\section{check for} updates

Citation: Wang, J.; Wang, C.; Zhang, H.; Tang, Y.; Duan, W.; Dong, L. Freeze-Thaw Deformation Cycles and Temporal-Spatial Distribution of Permafrost along the Qinghai-Tibet Railway Using Multitrack InSAR Processing. Remote Sens. 2021, 13, 4744. https://doi.org/ $10.3390 /$ rs13234744

Academic Editors: Annett Bartsch and Deodato Tapete

Received: 27 August 2021

Accepted: 18 November 2021

Published: 23 November 2021

Publisher's Note: MDPI stays neutral with regard to jurisdictional claims in published maps and institutional affiliations.

Copyright: (c) 2021 by the authors. Licensee MDPI, Basel, Switzerland. This article is an open access article distributed under the terms and conditions of the Creative Commons Attribution (CC BY) license (https:// creativecommons.org/licenses/by/ $4.0 /)$.

\begin{abstract}
The Qinghai-Tibet Railway (QTR) is the railway with the highest elevation and longest distance in the world, spanning more than $1142 \mathrm{~km}$ from Golmud to Lhasa across the continuous permafrost region. Due to climate change and anthropogenic activities, geological disasters such as subsidence and thermal melt collapse have occurred in the QTR embankment. To conduct the largescale permafrost monitoring and geohazard investigation along the QTR, we collected 585 Sentinel-1A images based on the composite index model using the multitrack time-series interferometry synthetic aperture radar (MTS-InSAR) method to retrieve the surface deformation over a $3.15 \times 10^{5} \mathrm{~km}^{2}$ area along the QTR. Meanwhile, a new method for permafrost distribution mapping based on InSAR time series deformation was proposed. Finally, the seasonal deformation map and a new map of permafrost distribution along the QTR from Golmud to Lhasa were obtained. The results showed that the estimated seasonal deformation range of the $10 \mathrm{~km}$ buffer zone along the QTR was $-50-10 \mathrm{~mm}$, and the LOS deformation rate ranged from -30 to $15 \mathrm{~mm} / \mathrm{yr}$. In addition, the deformation results were validated by leveling measurements, and the range of absolute error was between 0.1 and $4.62 \mathrm{~mm}$. Most of the QTR was relatively stable. Some geohazard-prone sections were detected and analyzed along the QTR. The permafrost distribution results were mostly consistent with the simulated results of Zou's method, based on the temperature at the top of permafrost (TTOP) model. This study reveals recent deformation characteristics of the QTR, and has significant scientific implications and applicational value for ensuring the safe operation of the QTR. Moreover, our method, based on InSAR results, provides new insights for permafrost classification on the Qinghai-Tibet Plateau (QTP).
\end{abstract}

Keywords: Qinghai-Tibet Railway; MTS-InSAR; permafrost distribution; seasonal deformation

\section{Introduction}

Permafrost is the soil that stays frozen, with a temperature remaining at or below $0{ }^{\circ} \mathrm{C}$, for at least two consecutive years [1]. The Qinghai-Tibet Plateau (QTP) permafrost area is approximately 1.5 million $\mathrm{km}^{2}$, which is the highest and most extensive permafrost in low-middle latitudes on Earth [2-4]. Due to climate change and anthropogenic interference, permafrost has been degraded over a significant area in recent years $[5,6]$. The thermal state of permafrost is sensitive to changing climatic conditions, especially increasing air temperatures [7]. Therefore, such changes in permafrost will have serious consequences for ecosystems, hydrological systems, and infrastructure integrity [8]. In particular, due to the construction and operation of the Qinghai-Tibet Railway (QTR), the Qinghai-Tibet Highway (QTH), oil and gas pipelines, and the impacts of human activities on the QTP, the local topography, the surface conditions of frozen soil (vegetation, snow cover, and water), and 
the physical properties of the shallow layers of the ground have changed dramatically $[9,10]$. Therefore, the thermal state of the permafrost and the long-term stability of the roadbed are facing great challenges, and these changes may trigger geohazards along the QinghaiTibet Engineering corridor [11]. The QTR is the highest-elevated and longest railway across a permafrost region in the world [12]. Permafrost subsidence is a common hazard affecting the stability of railway embankment. Moreover, the temporal-spatial distribution of permafrost is a major component of cryosphere research. Seasonally frozen ground and permafrost are widely distributed along the QTR, and their deformation laws are different. The deformation laws of the freeze-thaw cycles of different types of frozen soil are closely related to the permafrost distribution. Therefore, it is of great scientific significance to conduct long-term deformation monitoring and large-scale permafrost research along the QTR, and it is also necessary to study the distribution characteristics of frozen soil and to evaluate the influence of temporal-spatial changes of frozen soil on regional climate system [13].

Traditional geodetic measurement methods of permafrost along the Qinghai-Tibet Engineering corridor include leveling surveys [14], global navigation satellite system (GNSS) surveys [15], and drilling [16]. These methods can obtain the single-point and highprecision measurement results of the Qinghai-Tibet Engineering corridor [17]. However, the results can only be obtained at limited sections, and it is also difficult and time-consuming to measure in the harsh environmental plateau [18].

Synthetic aperture radar interferometry (InSAR) is a useful tool to investigate large and hard-to-access permafrost areas with high spatial and temporal resolutions, wide coverage, and frequent acquisitions of SAR images [19-21]. Several studies have demonstrated the ability of differential SAR interferometry (DInSAR) to detect ground displacements at millimeter to centimeter scales, and monitor ground movement related to freezing/thawing over permafrost regions of the QTP [19,22-24]. However, there are some limitations that the DInSAR technique encounters to measure the movement of permafrost, such as atmospheric disturbances [25], temporal decorrelation [21,26,27], and nonlinear motion trends caused by seasonal deformation of the active layer above the permafrost $[28,29]$. The persistent scatterer interferometry (PSI) technique [30] is used to retrieve the slow surface deformation in frozen soil regions by extracting highly coherent permanent scatterer (PS) points [31]. SBAS-InSAR technology [32], with small spatial-temporal baseline interferograms, has greatly improved the density of the measurement points in alpine steppe and alpine meadow areas of the QTP $[24,33]$. Due to the surface deformation of permafrost is a complex physical process, and the linear deformation model is generally adopted to retrieve the ground deformation in time series InSAR analysis. To describe the freezing and thawing processes of permafrost, a series of deformation models are proposed, such as a sinusoidal or cosinoidal model [34,35], a seasonal deformation model based on the square root of the accumulated degree days of thaw [18,36,37], and a normalized composite index based on the two seasonal coefficients (subsidence/uplift), as well as linear deformation trends [31,33] and a deformation model considering both the external (mainly climatic) and the internal factors (such as tectonic activities and thermal character) [38].

Recent studies have highlighted the potential of multitemporal radar interferometry (MT-InSAR) to detect and monitor the seasonal ground displacements caused by freezing and thawing processes of the active layer of permafrost [19,24,29,33,39]. Deformation monitoring of the QTR and QTH is carried out using multisource SAR data $[18,40]$. The active layer thickness (ALT) inversion model based on seasonal deformation, soil moisture, and soil porosity are established to derive the ALT [35,37,41-43]. The MT-InSAR technology also provides continuous measurements of surface displacements at a large scale and over a long period in permafrost regions $[19,44]$, and monitors surface deformation and permafrost degradation over a discontinuous permafrost terrain [29,45]. The recent launch of Sentinel-1A/B satellites with a short revisit time enables scientists to study the seasonal and inter-annual deformation of frozen soil in greater detail $[19,24,44]$. A considerable number of studies on deformation monitoring along the QTR mostly focus on some sections 
of the QTR at the regional scale $[18,22,23,28,40,46,47]$, and little attention has been paid to the freeze-thaw cycles of seasonal deformation of the whole QTR.

On the other hand, to effectively understand permafrost distribution and estimate future permafrost degradation, some researchers in the field of cryopedology are devoted to the study of permafrost distribution mapping [48-51]. They compile many permafrost maps by using multi-source datasets based on mathematical and physical models to evaluate the distribution and thermal states of frozen soil on the QTP in different periods [52]. With the development of remote sensing and Geographic Information System (GIS) technology, permafrost models are gradually improved, and the new maps of permafrost distribution on the QTP have been compiled [53,54]. Although these physical or mathematical models provide good permafrost distribution maps, these models with many parameters (such as surface temperature, vegetation coverage, snow depth, annual average ground temperature, soil moisture, altitude, and so on) are complicated and computationally intensive. Furthermore, some approaches are based on field observation data, which are difficult to obtain, and the spatial resolutions of permafrost distribution maps are low. For example, Zou et al. [53] proposed the permafrost distribution map with a resolution of $1 \mathrm{~km}$ based on the Temperature at the Top of The Permafrost (TTOP) model and remote sensing technology.

The abovementioned literature demonstrates the usefulness of InSAR in retrieving ground deformation of the QTR and the effectiveness of model methods in permafrost distribution mapping. However, none of these studies take advantage of InSAR deformation results to study the seasonal deformation characteristics in such wide coverage of entire QTR and explore the study of permafrost distribution mapping.

The purpose of this study aims to employ the multitrack time-series interferometry synthetic aperture radar (MTS-InSAR) method based on a composite index model to retrieve the ground displacement and map permafrost distribution from the Golmud to Lhasa section along the QTR. Firstly, 585 scenes of the Sentinel-1 dataset from March 2017 to March 2020 are collected to implement the InSAR process. Secondly, the deformation maps over a $3.15 \times 10^{5} \mathrm{~km}^{2}$ area along the QTR are obtained. Subsequently, some geohazard-prone sections of the QTR are determined, and the freeze-thaw deformation cycles, combined with the daily air temperature data and deformation results, are analyzed. Finally, the unsupervised classification method of Iterative Self-Organizing Data Analysis Technique (ISODATA) based on an InSAR time series deformation is used to map permafrost distribution along the QTR.

\section{Study Area and Dataset}

\subsection{Study Area}

Figure 1a shows that the study area is located in the eastern part of the QTP. The elevation ranges from 2700 to $7000 \mathrm{~m}$ (see Figure $1 \mathrm{~b}$ ), covering an area of approximately $8.97 \times 10^{5} \mathrm{~km}^{2}\left(89.319-96.524^{\circ} \mathrm{E}, 27.838-37.938^{\circ} \mathrm{N}\right)$. The QTR starts in Golmud, passes through Xidatan Basin, Kunlun Mountain, Budongquan, Wudaoliang, Beiluhe, Fenghuoshan, Tuotuohe, crosses Tanggula Mountain, goes through Amdo, Naqu, Damxung of Tibet, and ends at Lhasa, with a total length of $1142 \mathrm{~km}$, as shown in Figure 1b. The study area has typical and complete types of landforms, including alpine meadows, alpine deserts, alpine steppes, floodplains, glaciers, and lakes. The terrain is complex, including high-altitude mountains, plateaus, and basins. The mean annual ground temperature is higher than $-0.5{ }^{\circ} \mathrm{C}$, exceptionally lower than $-0.5^{\circ} \mathrm{C}$, and most of the active layer thickness is greater than $3 \mathrm{~m}$. The climatic types in the study area are arid and semiarid, which are characterized by the subtle seasons, low temperature with high altitudes, and more diurnal sunlight hours. The average annual air temperature in this region is $0{ }^{\circ} \mathrm{C}$, with the highest temperature recorded in July and the lowest temperature recorded in January or December. The freezing period lasts for 7-8 months. The annual precipitation in most areas along the QTR is $200-300 \mathrm{~mm}$, the rainy season is from May to September, and the dry season is from October to April [55]. 

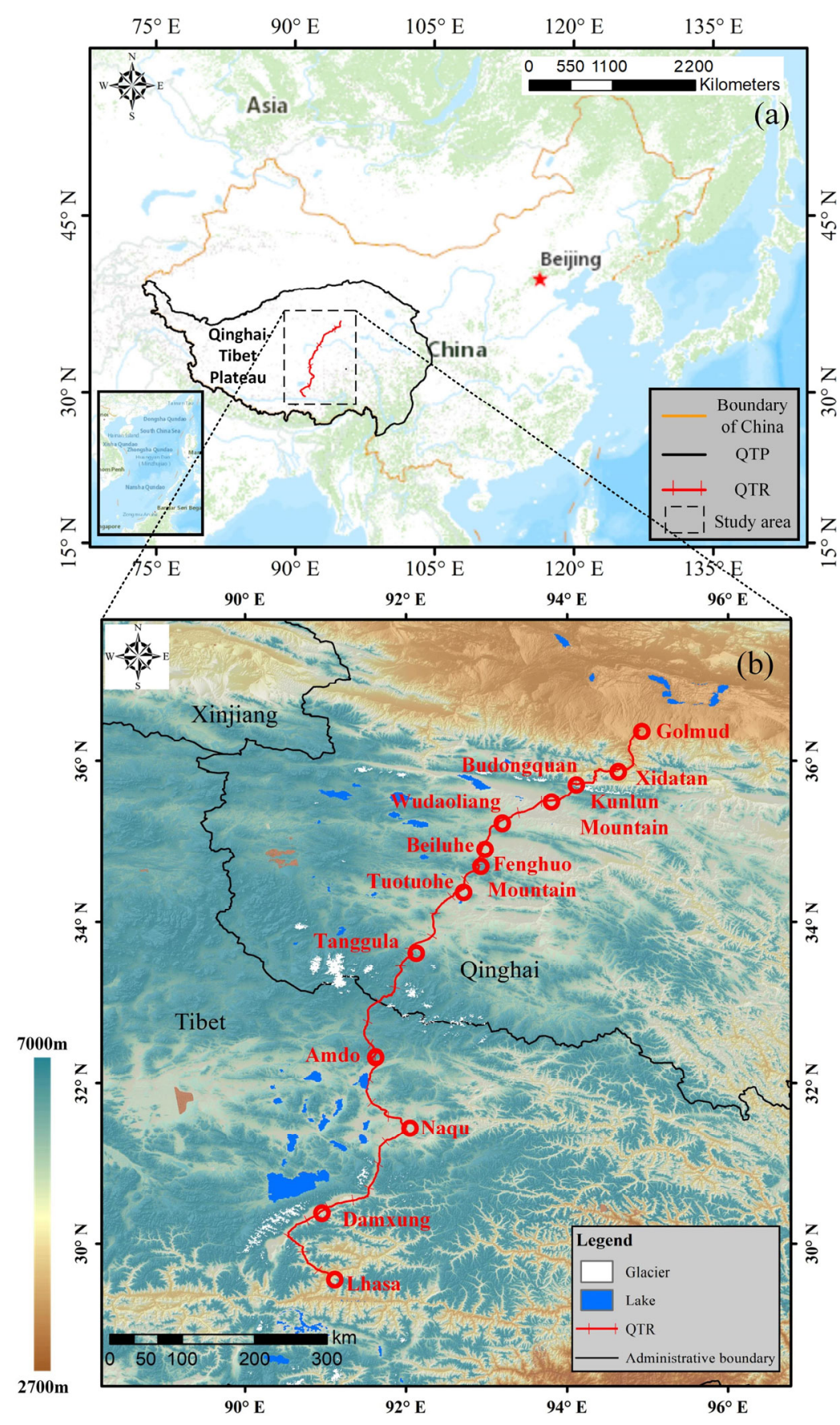

Figure 1. The location of study area and QTR in China. (a) Study area superimposed on the color map from ArcMap software. (b) Study area superimposed on a one arc-second Shuttle Radar Topography Mission (SRTM) digital elevation model (DEM) shaded topography map along the QTR, China.

\subsection{Qinghai-Tibet Railway}

The QTR is one of the four major projects in China's western development strategy. Figure 2 shows the QTR from Golmud to Lhasa, which started on 29 June 2001 and opened to traffic on 1 July 2006 [56]. Kunlun mountain tunnel with a length of $1686 \mathrm{~m}$ and an elevation of $4648 \mathrm{~m}$ is the longest plateau permafrost tunnel in the world. Tanggula station, with an altitude of $5072 \mathrm{~m}$, is located in the permafrost area of Tanggula Mountain, and is the highest railway station in the world. Fenghuo Mountain tunnel is located on the Fenghuo Mountain at an altitude of $5010 \mathrm{~m}$, with a total length of $1338 \mathrm{~m}$. It is currently the world's highest altitude tunnel across the permafrost region [57]. 


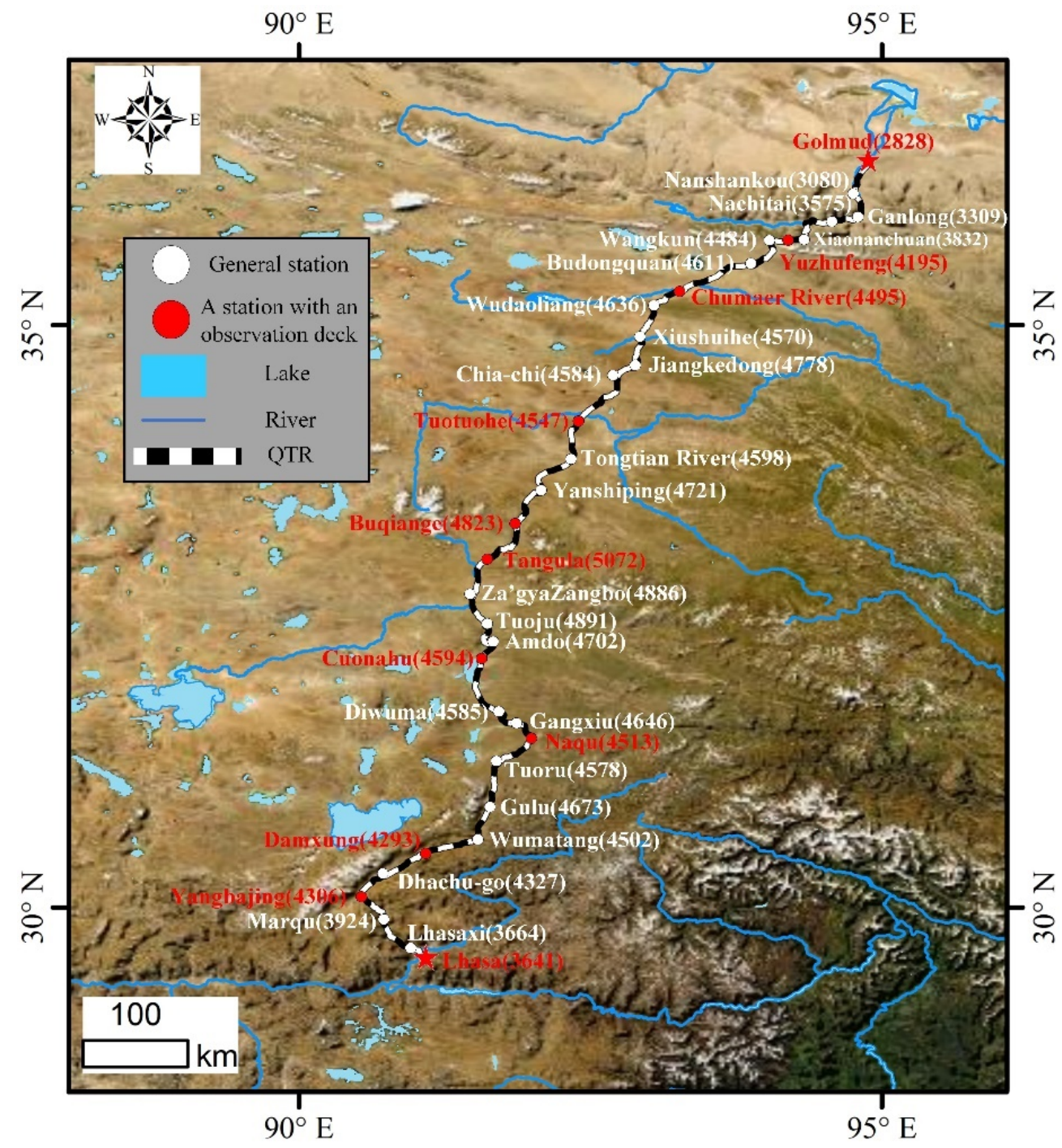

Figure 2. Schematic diagram superimposed on the world imagery map from the ArcMap software along the Golmud-Lhasa section of the QTR. The figure in brackets indicates the station's altitude.

Figure 3 shows the elevation profile and field photos of the section from Golmud to Lhasa of the QTR. The QTR crosses many high-altitude mountains, such as Hoh Xil Mountain, Kaixin Mountain, Fenghuo Mountain, Tanggula Mountain, Tou Erjiu Mountain, and Nyenchen Tanglha, respectively, etc. [58]. Other sections of the QTR belong to high plain landform with flat terrain. The rivers across the QTR include the Kunlun River, Chumaer River, Beiluhe, Tuotuohe, Yangtze River, Buqu River, Za'gya Zangbo River, Tongtian River, Nujiang River, and Yarlung Zangbo River (Figures 2 and 3).

The QTR has the following characteristics: active geological conditions, frequent tectonic movement, high altitude, strong sun radiation, and complex permafrost. The total length of the QTR in permafrost regions is approximately $550 \mathrm{~km}$, and approximately $82 \mathrm{~km}$ passes through discontinuous permafrost (Figure 3). Along the QTR, the area at an altitude of $4000 \mathrm{~m}$ high is $960 \mathrm{~km}$ long, accounting for $84 \%$ of the total length of the QTR, and the temperature is below $-10{ }^{\circ} \mathrm{C}$ in many places year-round [59]. The frozen soil layer thickness is greater than $60 \mathrm{~m}$, and the average active layer thickness ranges from $1.2 \mathrm{~m}$ to $4.9 \mathrm{~m}[55,59]$. 

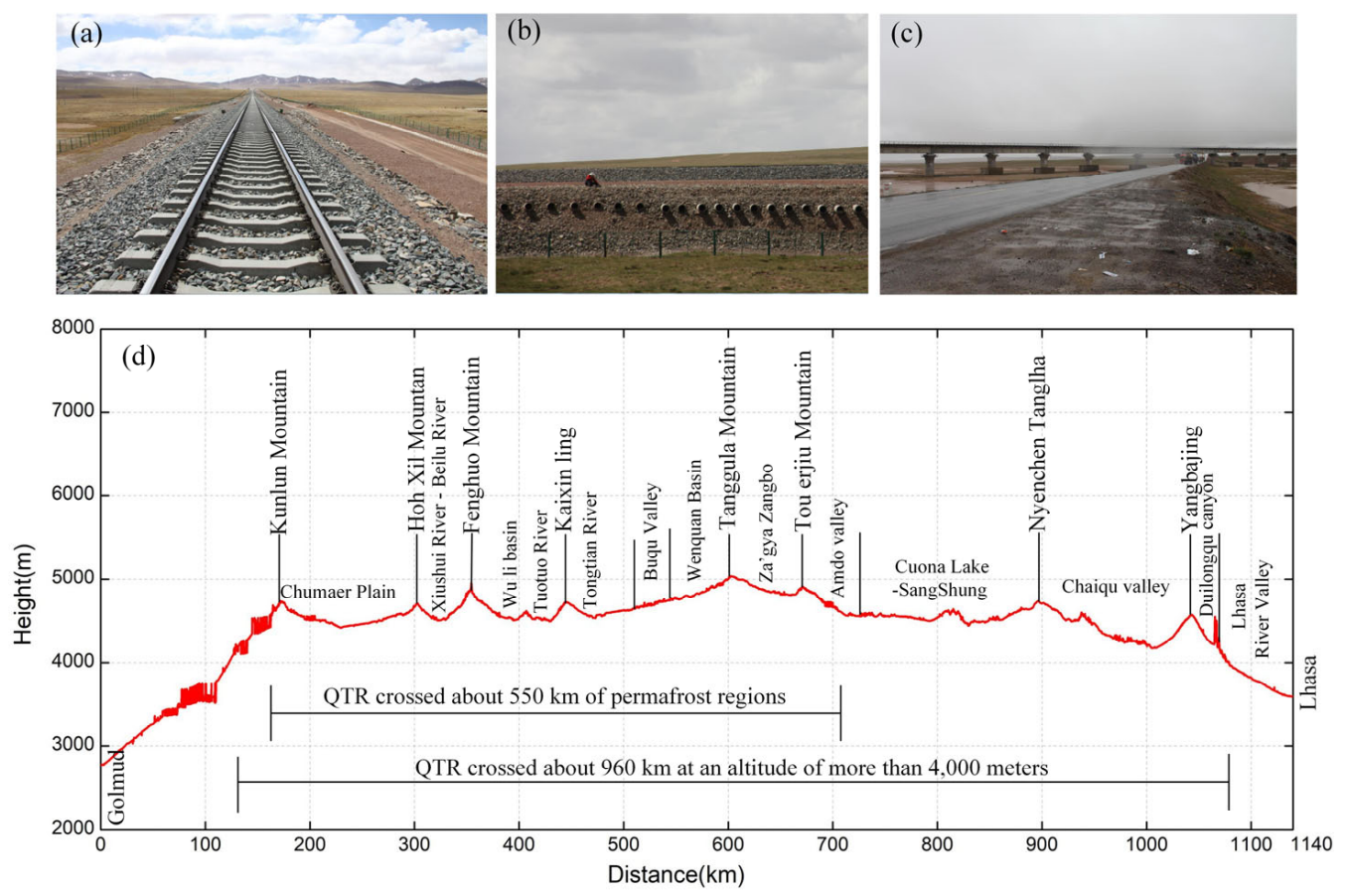

Figure 3. Vertical sectional profile graph and field photos of the QTR (from Golmud to Lhasa). $(\mathbf{a}-\mathbf{c})$ are field photos of the QTR. (d) is vertical sectional profile graph of the QTR.

The permafrost in Xidatan area is mostly island-shaped frozen soil. There are some glaciers and seasonal run-offs from the Kunlun Mountains. In recent years, due to rising temperatures and human activities, some glaciers have melted, and soil moisture has increased, causing subsidence in the area. The Budongquan-Hoh Xil section of the QTR, with an average elevation of approximately $4600 \mathrm{~m}$, is located between the north side of the Tanggula Mountains and the south side of the Kunlun Mountains. The QTR surrounding the Salt Lake is deteriorating at an accelerated rate [45] in the Hoh Xil region. Some researches show that serious surface deformation has occurred in the Wudaoliang-Beiluhe section of the QTR, with amplitudes up to $40 \mathrm{~mm}$ in recent years [24]. The terrain in Naqu is relatively flat, and there are thaw lakes nearby. The degradation of frozen soil and the influence of soil moisture may cause settlement in the area. There are some glaciers and various geothermal fields, and the average annual precipitation is $617.5 \mathrm{~mm}$ in Yangbajing area. Abundant rainfall and the migration of geothermal fluids in geothermal fields may have an impact along the QTR. The long-term observation of permafrost along the QTR has indicated that permafrost subsidence is a common hazard affecting the stability of the railway embankment [60]. Therefore, it is necessary to conduct real-time deformation and geological hazard monitoring along the QTR.

\subsection{Sentinel-1 Dataset}

A total of 585 scenes of descending Sentinel-1A TOPS SAR images along two adjacent tracks covering seven frames from 16 March 2017 to 24 March 2020, were collected to monitor surface deformation along the QTR. The coverage of Sentinel-1 images was approximately $3.15 \times 10^{5} \mathrm{~km}^{2}$, as shown in Figure 4 . Sentinel-1 SAR datasets were acquired by the novel interferometric wide swath (IW) TOPS mode, with a total swath width of $250 \mathrm{~km}$. The range and azimuth pixel spacing intervals were $2.33 \mathrm{~m}$ and $13.93 \mathrm{~m}$, respectively. There are 80 to 86 scenes for each frame, and the total data volume of the data is about 2340 GB. The detailed data information is shown in Table 1. 


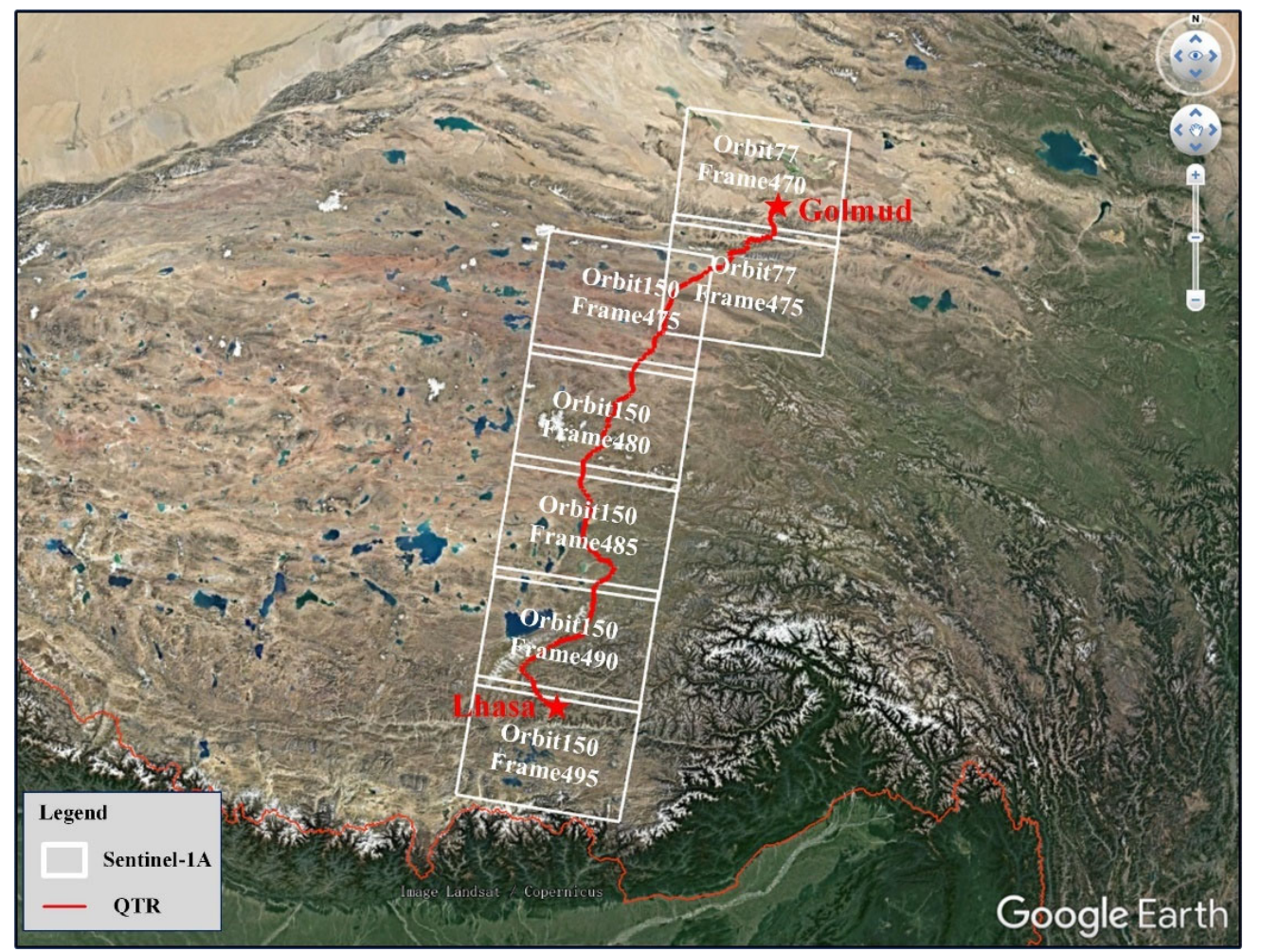

Figure 4. Coverage of Sentinel-1A SAR images. The white box indicates the coverage of Sentinel-1 data. The red line represents the QTR. The background map is from Google Earth.

Table 1. Detailed information for Sentinel-1A SAR data along the QTR.

\begin{tabular}{cccc}
\hline Sentinel-1 & Number of SAR Images & Angle of Incidence & Memory Occupied by Data \\
\hline Track 77 Frame 470 & 80 & 39.84 & $4 \mathrm{G} \times 80=320 \mathrm{G}$ \\
Track 77 Frame 475 & 81 & 39.37 & $4 \mathrm{G} \times 81=324 \mathrm{G}$ \\
Track 150 Frame 475 & 82 & 39.31 & $4 \mathrm{G} \times 82=328 \mathrm{G}$ \\
Track 150 Frame 480 & 84 & 39.80 & $4 \mathrm{G} \times 84=336 \mathrm{G}$ \\
Track 150 Frame 485 & 87 & 39.82 & $4 \mathrm{G} \times 87=348 \mathrm{G}$ \\
Track 150 Frame 490 & 85 & 39.86 & $4 \mathrm{G} \times 85=340 \mathrm{G}$ \\
Track 150 Frame 495 & 86 & 39.84 & $4 \mathrm{G} \times 86=344 \mathrm{G}$ \\
\hline
\end{tabular}

\section{Methodology}

This study employs the new small baseline subset (NSBAS) approach based on the composite index model to investigate the surface deformation of the QTR. The SavitzkyGolay (SG) filter algorithm [61] is used to smooth InSAR time-series deformation, and the ISODATA method [62] is applied to map permafrost distribution along the QTR.

The five main steps of the process are shown in Figure 5. This flowchart includes the main processing steps: (1) Sentinel-1 TOPS Image Preprocessing-GMTSAR software is used to implement the DEM co-registration and ESD co-registration of Sentinel-1 data [63]; (2) interferometry-all the Sentinel-1 interferograms are multi-looked by factors of 12 and 3 along the range and azimuth directions, respectively; (3) NSBAS flow-the GIAnT toolbox is adopted to execute the NSBAS inversion [64]; (4) merging seasonal deformation resultsfinally, the geohazard-prone sections of the QTR based on the seasonal deformation results are determined; and (5) mapping of permafrost distribution along the QTR. 


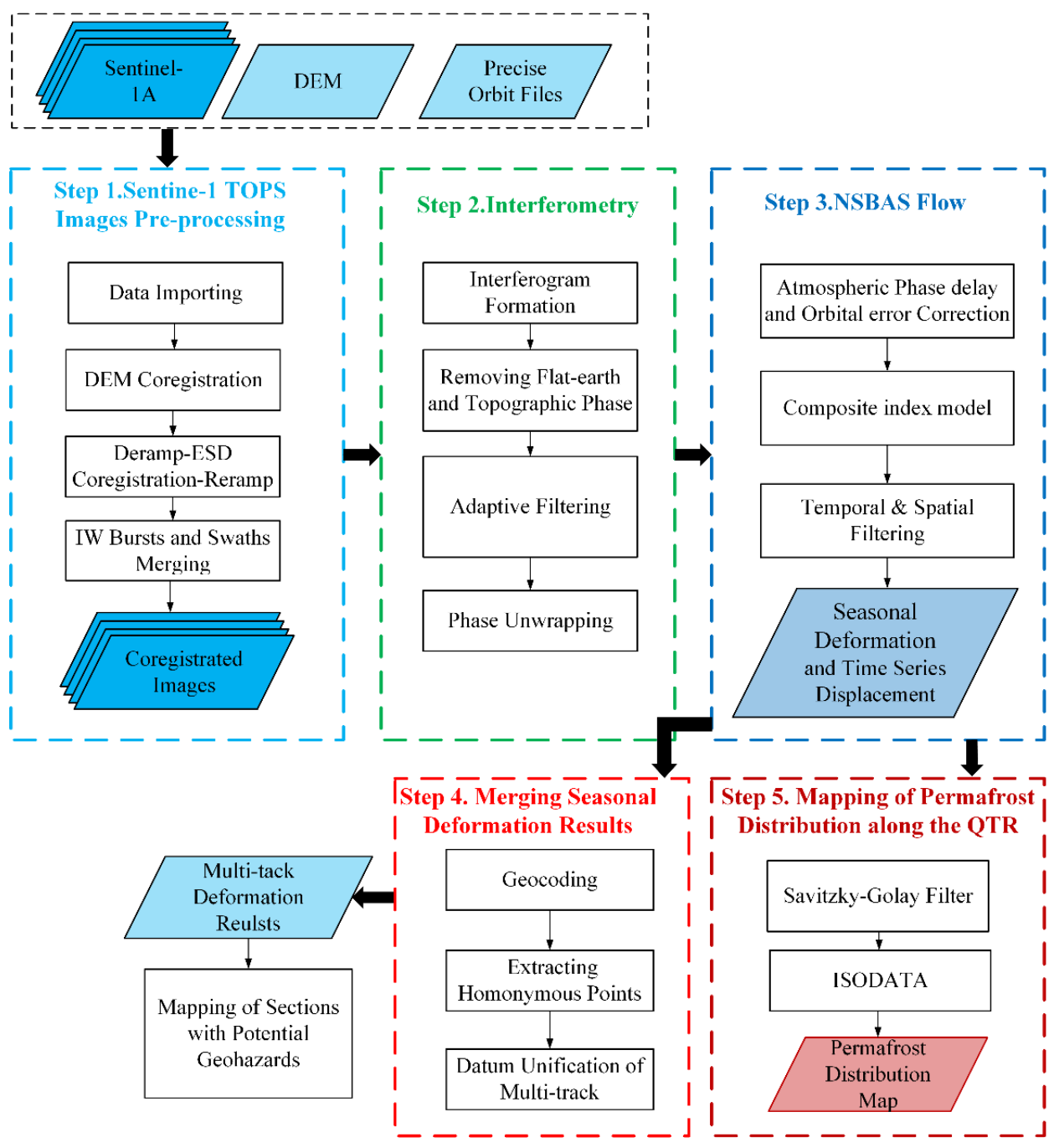

Figure 5. Flowchart of the MTS-InSAR processing approach.

\subsection{Composite Index Model Based on the NSBAS Method}

The calculation of this composite index model is explained in detail by Hu et al. [65], and is based on the daily averaged air temperature data in our study area by downscaling the ERA5 monthly averaged reanalysis product. A composite index deformation model based on Stefan's equation is used to approximate deformation of frozen soil. It includes thawing subsidence $(s(t))$ and freezing uplift $(u(t))$ and can be expressed as follows:

$$
d_{s}(t)=s(t)-u(t)=E_{T} \sqrt{A_{T}(t)}-E_{F} \sqrt{A_{F}(t)}
$$

where $d_{S}$ is the elevation at any given time $t$ during the annual thaw-freeze cycle. $E_{T}$ and $E_{F}$ are time-invariant coefficients based on the soil thermal conductivity, $\mathrm{n}$-factors (which are ratios accounting for the offset between the air temperature and the ground surface temperature), the accumulated degree days of thawing or freezing, the soil bulk density, the volumetric water content, and the specific latent heat of fusion for water [65].

Furthermore, the two seasonal coefficients $E_{T}$ and $E_{F}$ are related to a scaling factor $\alpha$ :

$$
\alpha=\sqrt{\frac{k_{F} n_{F}}{k_{T} n_{T}}}
$$


where $k_{F}$ and $k_{T}$ are the soil thermal conductivities that can be obtained from the local soil type and volumetric water content [42]. $n_{F}$ and $n_{T}$ can be calculated as shown by Cao et al. [66].

Based on Equations (1) and (2), the composite index $I(t)$ can be calculated as follows:

$$
I(t)=\sqrt{A_{T}(t)}-\alpha \sqrt{A_{F}(t)}
$$

where $A_{T}(t)$ and $A_{F}(t)$ are the square roots of the accumulated degree of thawing and freezing days associated with seasonal deformation, respectively, which can be calculated according to the 2-m air temperature [37].

The linear deformation model is modified by adding seasonal deformation and residual deformation. The observed deformation during SAR image acquisition dates can be expressed as the sum of the seasonal deformation and linear deformation changes in the thawing and freezing period as follows:

$$
d(t)=d_{s} I(t)+d_{v} t+c
$$

where $d(t)$ is the total surface deformation on any day $t$ since the onset of thawing or freezing; $d_{s}$ is the maximum seasonal subsidence $(\mathrm{mm}) ; d_{v}$ is the linear deformation rate $(\mathrm{mm} / \mathrm{yr}) ;$ and $c$ is the residual deformation between the observations and the fitted model.

\subsection{NSBAS Method}

For the given pixel $x$ in N interferograms of M SAR images, the unwrapped interferogram set was written as a linear combination of the phase values of each pixel of Sentinel-1 images, as shown in the following equation [67]:

$$
d_{x}=G_{x} m_{x} \Leftrightarrow \Phi_{x}^{i j}=\sum_{n=i}^{j-1} \delta \varphi_{n}
$$

where $d_{x}$ is the phase vector of pixel $x$ of $N_{x}$ interferograms; $G_{x}$ is a $N_{x} \times\left(M_{x}-1\right)$ matrix composed of $0,-1$ and 1 ; and $m_{x}$ is the phase increment composed of pixel $x$, namely, the unwrapped interferometric phase to be solved. $\Phi_{x}^{i j}$ is the phase of the unwrapped interferometric phase composed of pixels $x$ of the $i$-th and $j$-th SAR images, and $\delta \varphi_{n}$ is the phase increment of pixel $x$ between the SAR image acquisition times $n$ and $n+1$.

The above equation can be solved by least squares, and single value decomposition (SVD) can be used to solve when the matrix is singular [32]. However, the above equation has a rank defect problem; that is, a key link is missing in the interconnection of the interferogram network. In this case, the SAR data network connection is divided into two or more independent image groups, and some images or image groups are not connected. When SVD replaces the least square to invert the time series displacement, it sets the phase delay increment between successive image groups to zero [67]. Therefore, the time series deformation calculation will be biased. To overcome this defect, the NSBAS method adds constraints to optimize the deformation calculation in the deformation inversion process [67]. The cumulative phase delay $\varphi_{x}^{k}$ of pixel $x$ at time $\mathrm{k}$ is defined as follows:

$$
\begin{aligned}
& \varphi_{x}^{T}=V_{x}^{t}\left(t-t_{T}\right)+I(t) \cdot S+e_{x} B_{\perp}^{T}+c_{x}^{t} \\
& \varphi_{x}^{F}=V_{x}^{t}\left(t-t_{F}\right)+I(t) \cdot S+e_{x} B_{\perp}^{F}+c_{x}^{t}
\end{aligned}
$$

where $V$ represents the long-term linear deformation rate; $S$ represents the maximum seasonal subsidence; $e_{x} B_{\perp}$ is the DEM error associated with the perpendicular baseline; and $I(t)$ is the composite index combining the freezing and thawing processes. $t_{T}$ and $t_{F}$ are the starting times of thawing and freezing, respectively. The following constraints can be added to the deformation inversion. The seasonal deformation model is applied to NSBAS technology to calculate the seasonal deformation. 


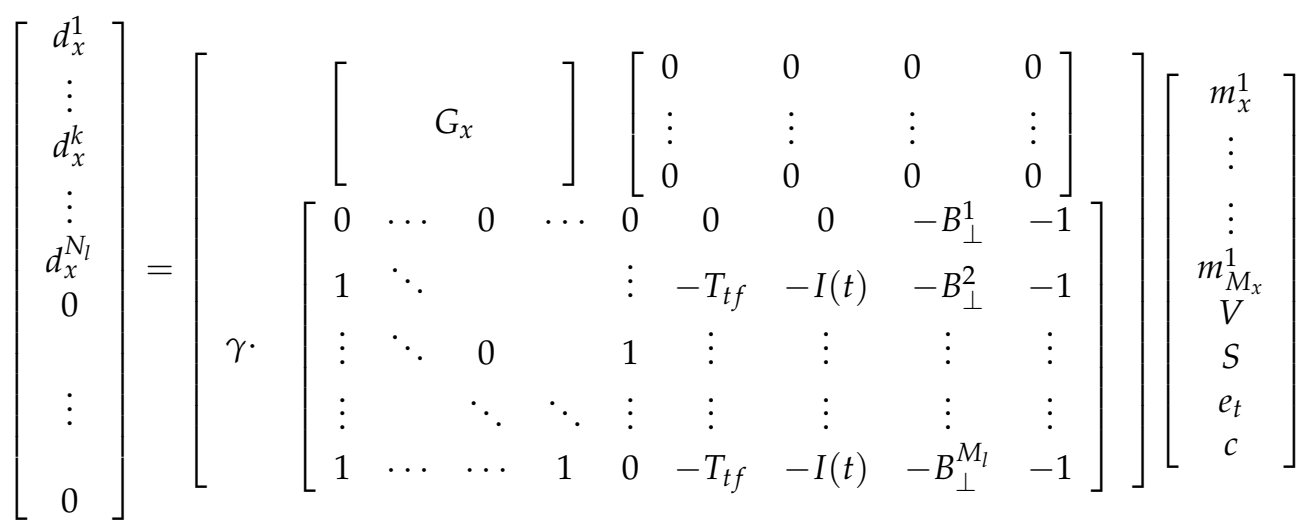

When $t_{T} \leq t \leq t_{F}$, it is in the thawing period, then $T_{t f}=t-t_{T}$; when $t>t_{F}$, $T_{t f}=t-t_{F}$. According to Equations (6) and (7), the least squares algorithm can be used to calculate the deformation parameters of frozen soil.

\subsection{Merging of Seasonal Deformation Results of Multi-Track Sentinel-1 Images}

Once the InSAR deformation results of each SAR image are obtained by using the NSBAS method, the InSAR results of different frames will be merged in the latitude and longitude geographic coordinate systems. Firstly, the deformation results are geocoded by using the range-Doppler (RD) geolocation algorithm to convert the SAR image in the azimuth-range coordinate system into geographic latitude and longitude coordinates [68]. Since the reference points of the multitrack deformation results are not consistent, there may be some differences in the multitrack overlapping area. It is necessary to adjust and mosaic the deformation results of multitrack Sentinel-1 data. Secondly, the same measurement points in multitrack overlapping areas based on geographic coordinates are extracted. Thirdly, the datum offset is calculated using Equations (8) and (9) [43] by analyzing the distribution of the homonymous point difference of the multitrack [69]:

$$
\begin{aligned}
& \bar{v}=\frac{\sum_{i=1}^{n}\left(v_{a i}-v_{b i}\right)}{n} \\
& \bar{S}=\frac{\sum_{i=1}^{n}\left(S_{a i}-S_{b i}\right)}{n}
\end{aligned}
$$

where $n$ is the number of homonymous measurement points in the overlapping area; $i$ is the $i$-th homonymous measurement point; and $a, b$ represent the deformation results of Sentinel-1 image $a$ and image $b$, respectively. $\bar{v}$ and $\bar{S}$ represent the average deformation rates and seasonal deformation of homonymous measurement points in the overlapping area of the adjacent tracks, respectively. vai and Sai are the deformation rates and seasonal deformation results of the $i$-th homonymous measurement point of the Sentinel-1 image $a$, respectively. $v_{b i}$ and $S_{b i}$ are corresponding value of the Sentinel-1 image $b$.

Finally, the InSAR results of image $a$ and image $b$ by these equations are merged. The multitrack Sentinel-1 results of different frames are spliced together.

\subsection{Permafrost Distribution Mapping Based on InSAR Time Series Deformation}

In this study, the ISODATA algorithm is implemented to classify the permafrost along the QTR, based on the time series InSAR deformation results. The time series deformation of each pixel may have residual topographic phase error, phase unwrapping error, noise error, and so on, after the MTS-InSAR process, thus it needs to be smoothed. Firstly, SG filtering algorithm is used to preprocess the time series deformation, which can better retain the original characteristics of signals [61]. Then, the permafrost is classified according to the filtered time series deformation. Since the deformation law of permafrost 
and seasonally frozen ground is complex and unpredictable, the unsupervised classification ISODATA method is adopted to classify frozen soil [62]. Compared with the K-means algorithm, ISODATA algorithm has the following advantages: it does not need to artificially specify the number of permafrost clusters; and it can dynamically merge or split classes, automatically adjust the number of clusters, and divide sample data into good cluster results by iterative operation [70]. The detailed process of the ISODATA algorithm can be seen in the literature $[62,70,71]$.

\section{Results and Analysis}

\subsection{Seasonal Deformation Results along the QTR}

The MTS-InSAR method based on the composite index model was used to retrieve the deformation of the QTR. The seasonal results are shown in Figure 6. Figure 6a shows that the amplitude range of the seasonal deformation of the study area is between -70 and $20 \mathrm{~mm}$ from 16 March 2017 to 24 March 2020. The seasonal deformation variation is mainly caused by the seasonal freezing uplift and thawing settlement of the active layer on the QTP [33]. The range of the seasonal deformation in most areas is between -30 and $10 \mathrm{~mm}$. The areas with higher seasonal deformation are mainly distributed around Salt Lake in the Budongquan area, Wudaoliang, Beiluhe, Tuotuohe, Tanggula Mountain pass, and around Namco Lake. The LOS velocity shown in Figure $6 \mathrm{~b}$ ranged from -40.0 to $20.0 \mathrm{~mm} / \mathrm{yr}$, and it is related to thawing of ice-rich permafrost near the permafrost table. The secular subsidence trend is stable. Figure 7 shows that the range of DEM error is between -60 and $60 \mathrm{~m}$. The mean and standard deviation of the DEM error are -1.98 and 26.32 , respectively. The DEM error estimation in most of the study areas is consistent with the relative accuracy of the SRTM DEM.
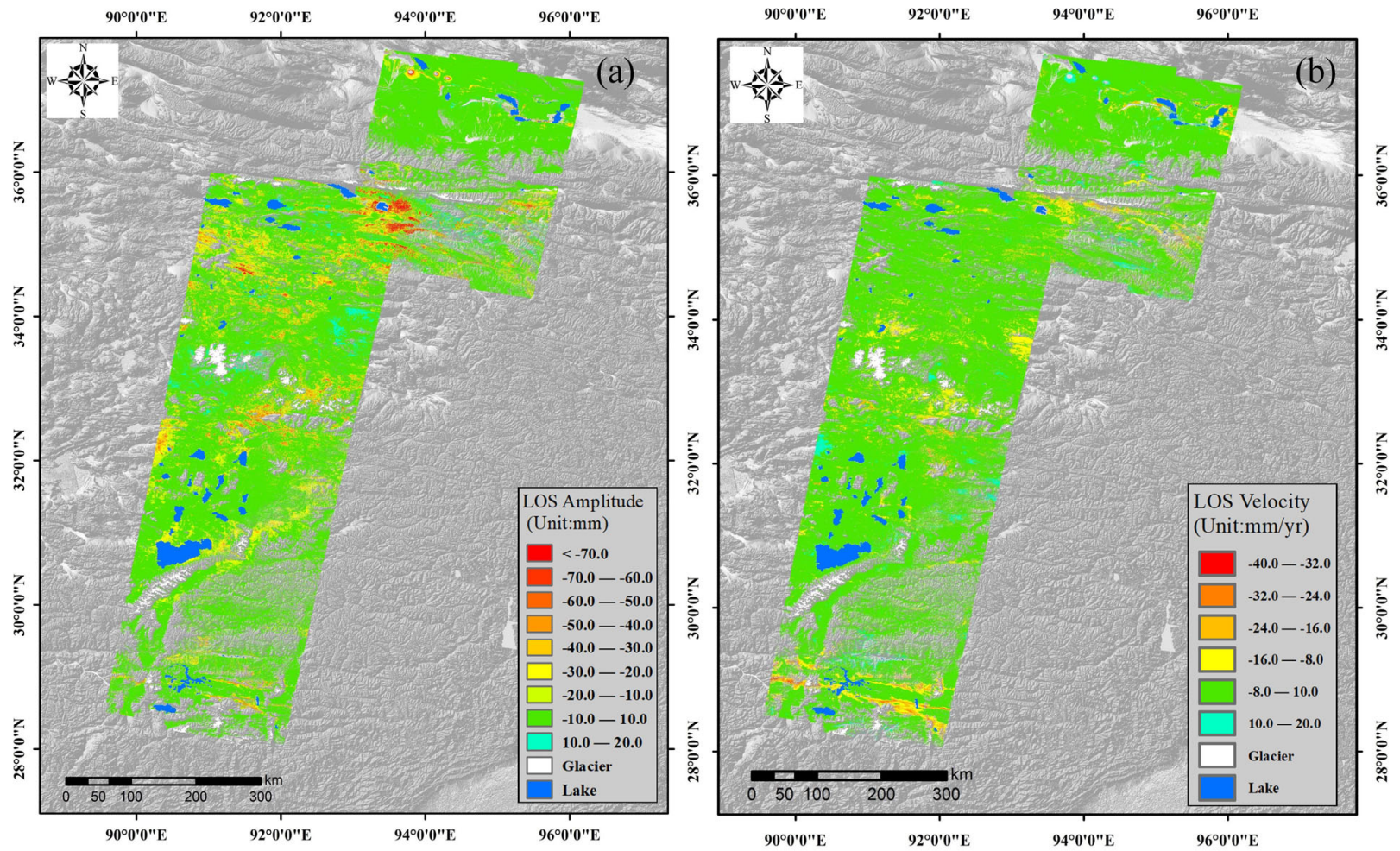

Figure 6. Deformation results of the study area. (a) Amplitude of seasonal deformation. (b) LOS velocity. 

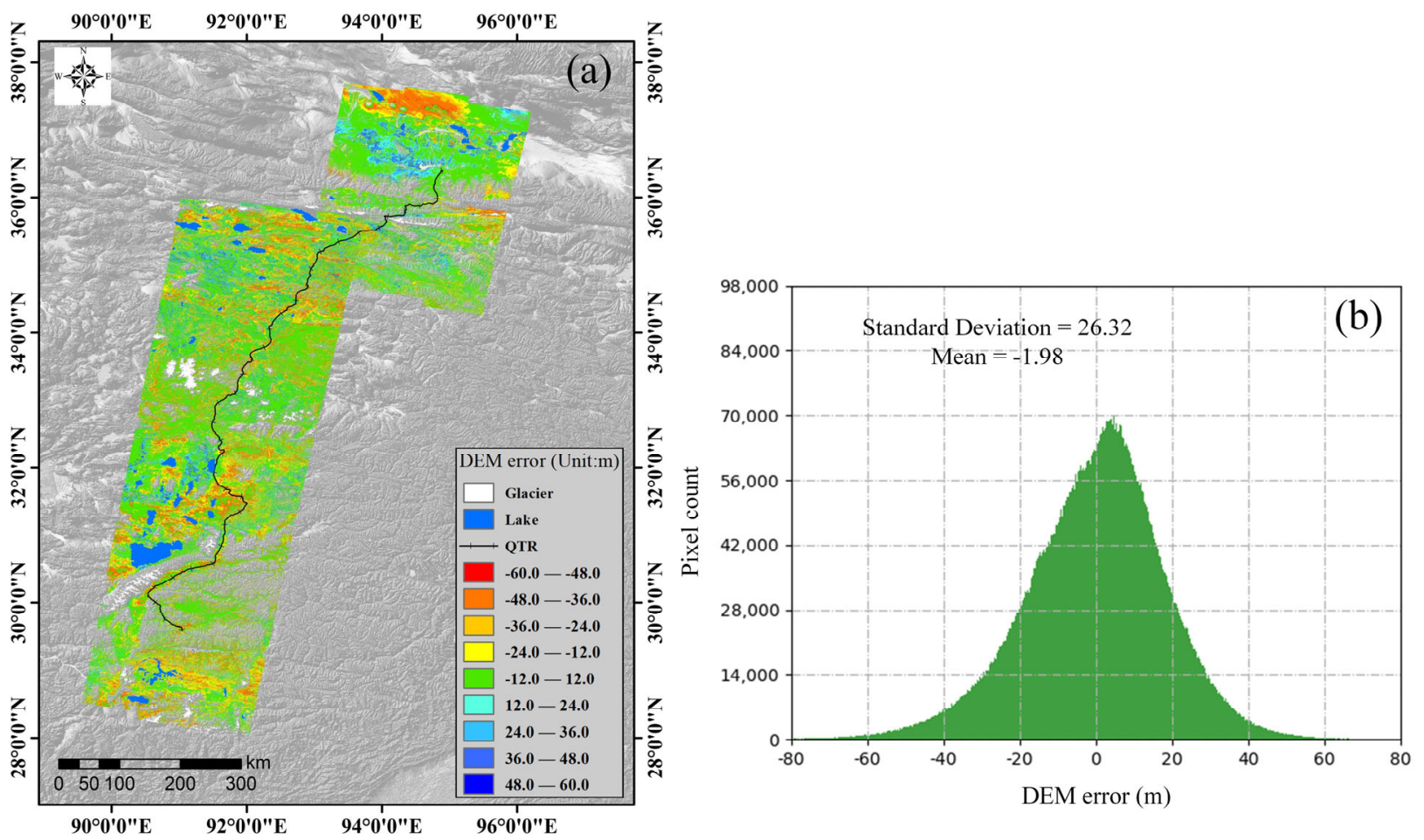

Figure 7. DEM error map in the study area. (a) DEM error distribution map. (b) Frequency distribution histogram of DEM error.

The DEM map, slope map, seasonal deformation map, and deformation rate map of the $10 \mathrm{~km}$ buffer zone along the QTR were extracted as shown in Figure 8. Figure 8a,b show that the average elevation of the QTR from Golmud to Xidatan is relatively low $(2700 \mathrm{~m})$ and that the slope is relatively steep. Starting from the Kunlun Mountain pass, the average elevation uplifts to approximately $4000 \mathrm{~m}$. In the middle section of the QTR, the average elevation near the Tanggula Mountain Pass is approximately $5000 \mathrm{~m}$, with a relatively large slope. In the Damxung and Yangbajing areas, the slope is 50-60. The average elevation is $3600 \mathrm{~m}$ in Lhasa. Figure $8 \mathrm{c}$ shows that the seasonal deformation ranged from -50 to $10 \mathrm{~mm} / \mathrm{yr}$. Human activities, such as subgrade construction and railway operation, destroy the original thermal balance of the active layer, leading to obvious subsidence of the permafrost surface. The sections with high subsidence values include Golmud-Xidatan, Budongquan-Hoh Xili, Wudaoliang-Wuli, Tuotuohe-Yanshiping, Tanggula Mountain pass-Amdo, Naqu-Damxung, and Yangbajing-Lhasa. Figure 8d shows that the range of the deformation rate is between -30 and $15 \mathrm{~mm} / \mathrm{yr}$ along the QTR, and its details are zoomed in Figure 9 for different sections of QTR.

To further analyze the spatial distribution characteristics and the trends of the deformation results in the study area, the spatial analysis tool of ArcGIS 10.6 software was used to conduct spatiotemporal analysis. The $\mathrm{MN}$ rectangular profile extends from northern Golmud city to the Lhasa area, while the PQ rectangular profile extends from the western foot of Kunlun Mountain to southern Naqu. The relationship between the amplitude of the seasonal deformation and LOS deformation rate and elevation are shown in Figure 10. The profile zones $\mathrm{MN}$ and $\mathrm{PQ}$ were divided into 300 and 200 subregions, and then the mean seasonal deformation results in these subregions were extracted. Figure 10 shows that the areas with high amplitudes of seasonal deformation are mainly concentrated in Xidatan (B), Wudaolang (C), Beiluhe (D), Fenghuo Mountain (E), Tuotuohe (F), Tanggula Mountain Pass (G), Amdo (H), Naqu (I) and Damxung (J). The amplitudes of seasonal deformation in Golmud (A) and Lhasa (K) are lower, and the corresponding deformation rates in these areas are also higher. Due to the uneven distribution of seasonal permafrost and permafrost in the study area, the seasonal deformation and deformation rate are different. 

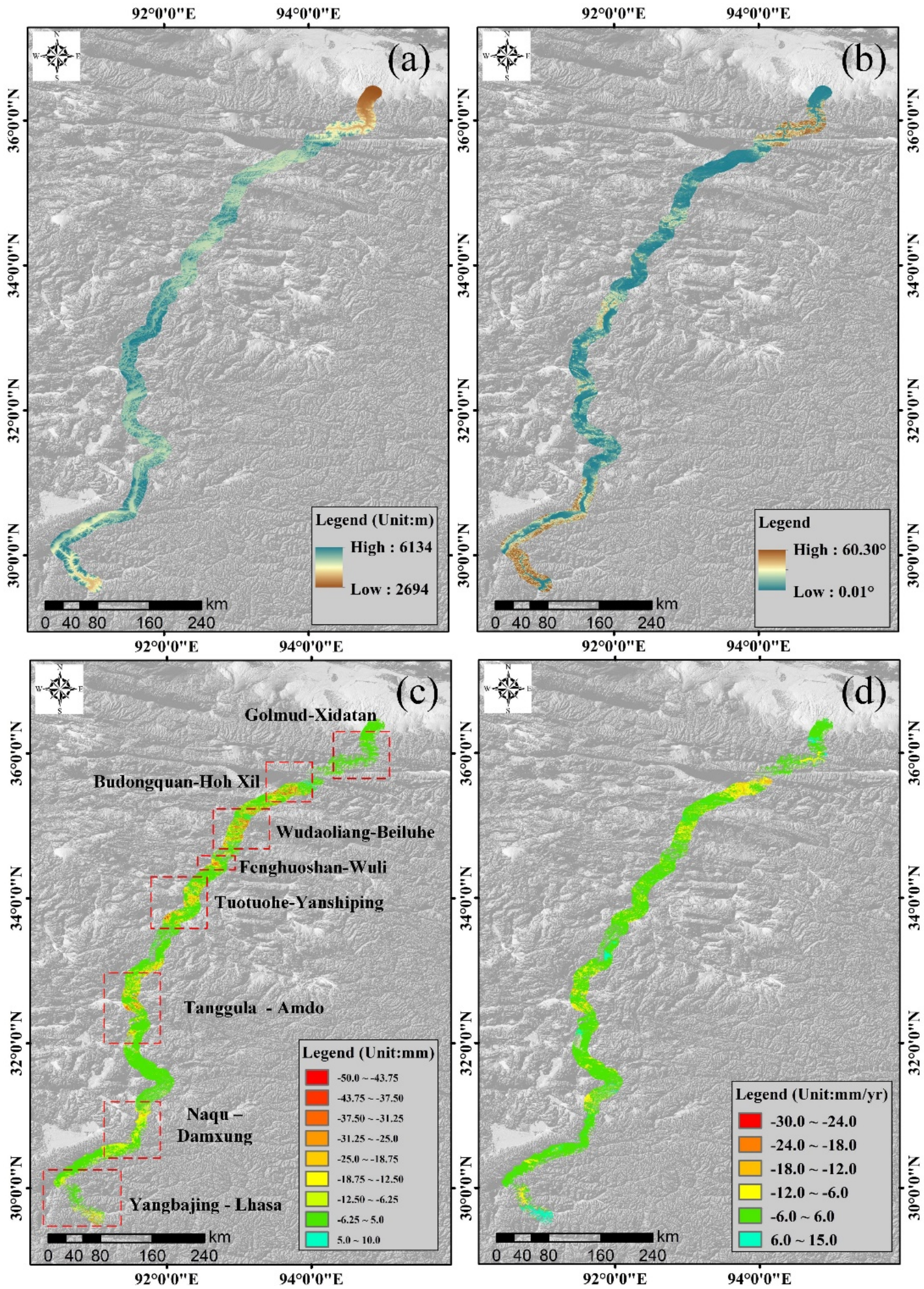

Figure 8. Deformation results along QTR buffer. (a) DEM map along QTR buffer. (b) Slope map along QTR buffer. (c) Seasonal deformation map along QTR buffer. (d) LOS deformation rate map along QTR buffer. 

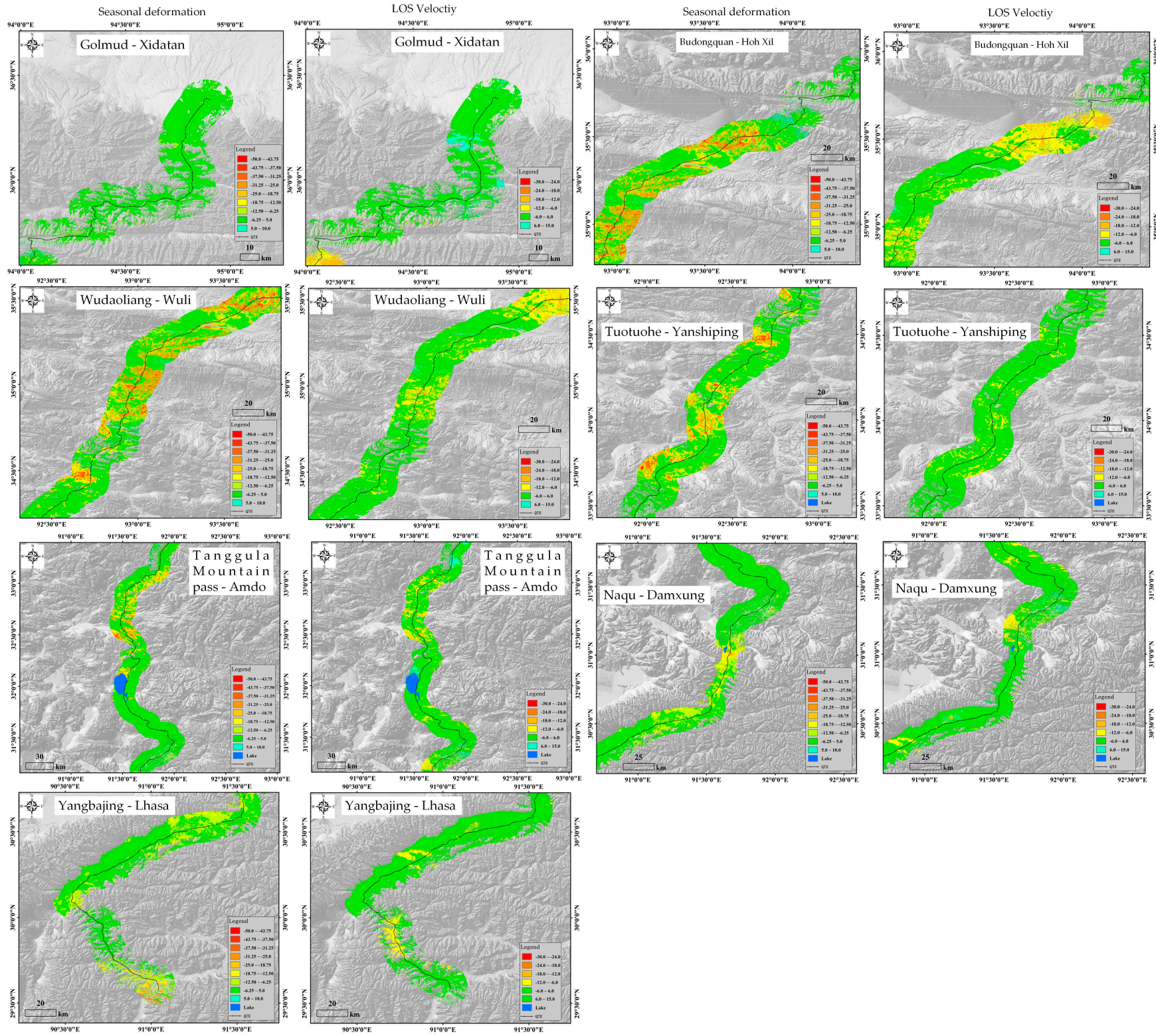

Figure 9. A magnified view of deformation results of these geohazard-prone sections.

The deformation results are extracted along the QTR, as shown in Figure 11. The amplitude of the seasonal deformation along the QTR ranges from -30 to $15 \mathrm{~mm}$. The LOS deformation rate ranges from -20 to $20 \mathrm{~mm} / \mathrm{yr}$. The sections with higher seasonal deformation are the BC section (Xidatan to Wudaolang), CD section (Wudaolang to Beiluhe), DE section (Beiluhe to Fenghuo Mountain), and EF section (Fenghuo Mountain to Tuotuohe), as shown in Figure 11. The sections with small seasonal deformation are the GH (Tanggula to Amdo), HI (Amdo to Naqu), IJ (Naqu to Damxung), and JK (Damxung to Lhasa) sections. There is a negative correlation between the seasonal deformation trend and elevation. Since solid precipitation or snowmelt leads to small changes in soil moisture, the hydrothermal properties remain stable, and the deformation values are low in these high-altitude areas. However, Daout et al. pointed out that frozen soil deformation has little relationship with elevation [44]. The reason for this trend is that most of the high-altitude areas are mountains, which are composed of stable bedrock, and the seasonal deformation is small, while the seasonal deformation in the low-altitude areas is related to soil moisture, soil properties, vegetation coverage, active layer thickness, etc. 

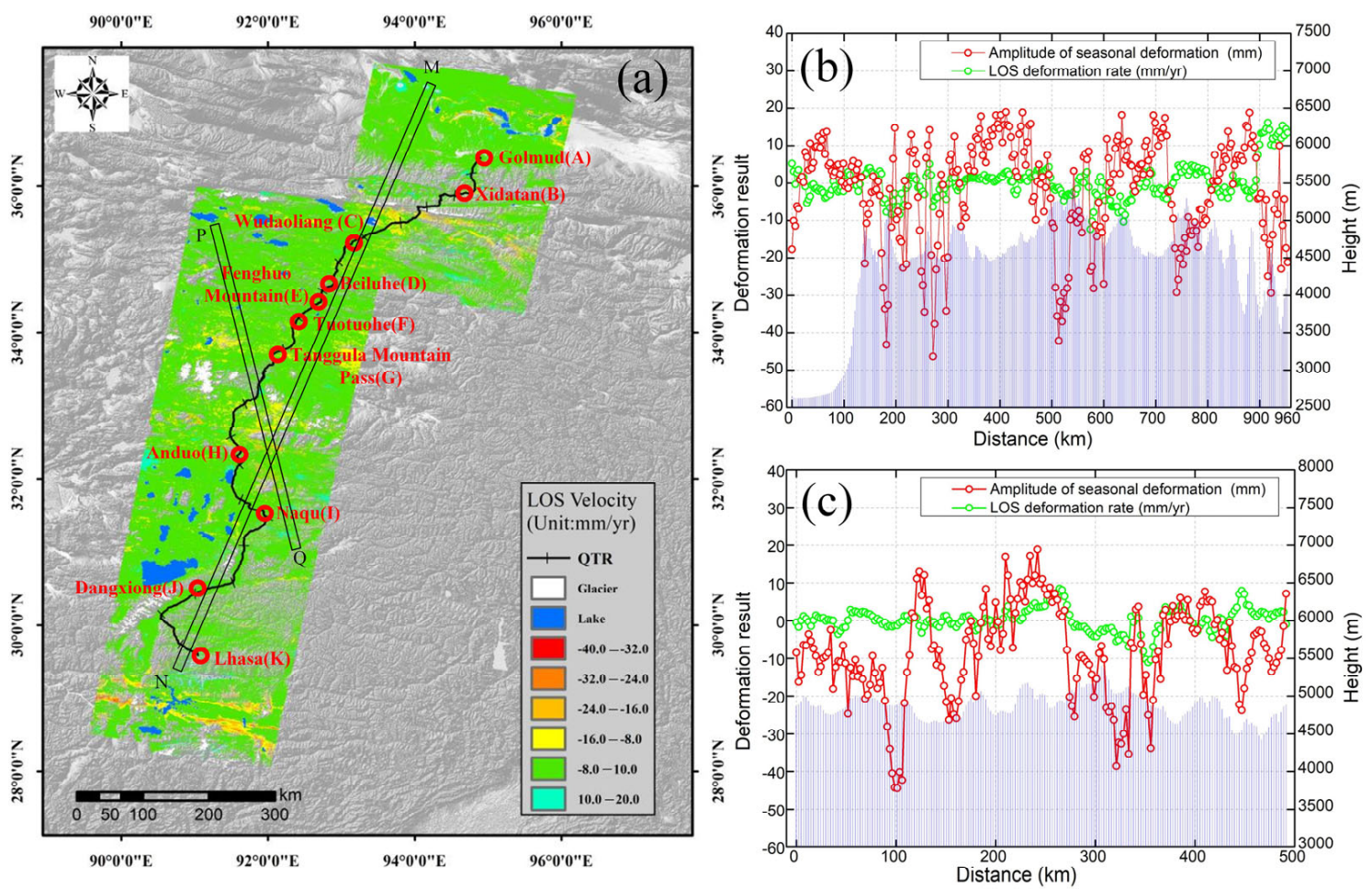

Figure 10. Relation between the height, amplitude of the seasonal deformation and LOS deformation rate along the $\mathrm{MN} \backslash \mathrm{PQ} \backslash \mathrm{QTR}$ profile. (a) Geographic location along MN $\backslash \mathrm{PQ} \backslash \mathrm{QTR}$ profile. (b) Height and amplitude of the seasonal deformation and LOS deformation rate profile along M to N. (c) Height and amplitude of the seasonal deformation and LOS deformation rate profile along $\mathrm{P}$ to $\mathrm{Q}$.
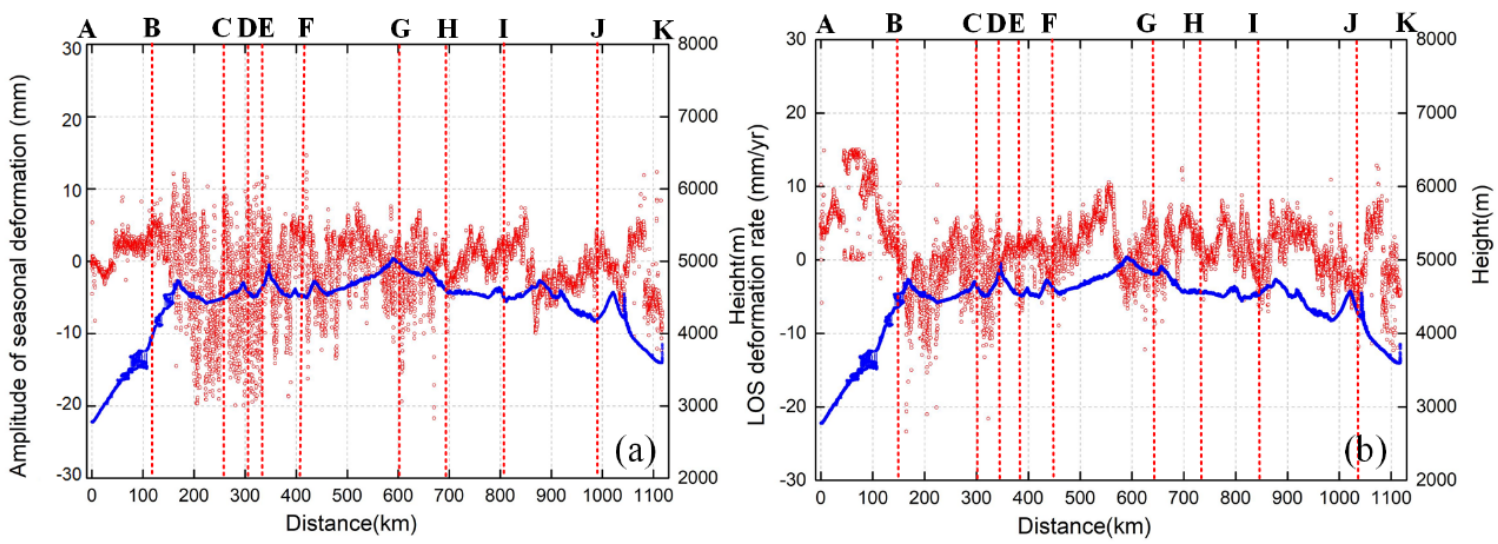

Figure 11. Relationship between the height, amplitude of the seasonal deformation and LOS deformation rate along the QTR profile. (a) Height and amplitude of the seasonal deformation profile along the QTR profile. (b) Height and LOS deformation rate along QTR profile.

\subsection{Spatial Distribution and Deformation Factors Analysis of the Geohazard-Prone Sections}

In this section, to explore the deformation factors of the $10 \mathrm{~km}$ buffer zone along the QTR, a detailed analysis of several geohazard-prone sections of the QTR is performed.

\subsubsection{Xidatan}

Figure 12 shows an enlarged view of the seasonal deformation and Google map in the Xidatan area, which is located in the glacial alluvial plain of Kunlun Mountain. The high seasonal deformation are mainly distributed on the glacier outwash plains and floodplain region, namely, region A and region B. Figure $12 \mathrm{~b}$ shows the floodplain area with relatively 
seasonal amplitude of $31.50 \mathrm{~mm}$, where the scouring of rivers forms a thawing zone around the riverbed. Yuzhu peak is the highest peak in the eastern part of the Kunlun Mountains. The melting of glaciers is greater than accumulation, and Yuzhu peak belongs to the retreating continental glaciers. The top of the mountain is covered by snow and ice, and there are several seasonal runoffs from Yuzhu peak caused by melting glacier water (see Figure 12c). Therefore, seasonal deformation factors may be likely associated with an increase of water or ice volume within areas characterized by high water accumulation, increased precipitation, permafrost thawing, or glacial recession.

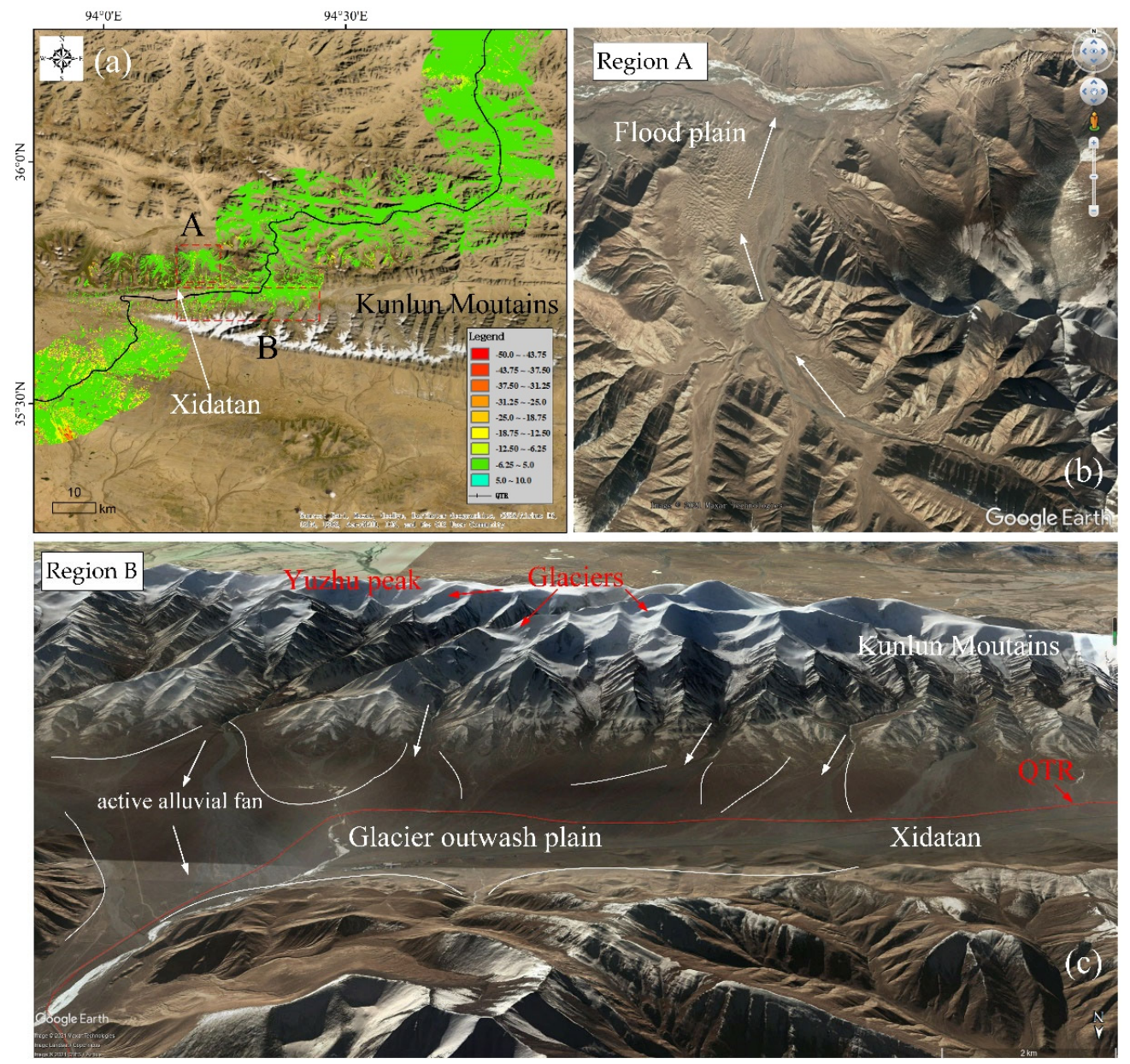

Figure 12. Deformation analysis map for Xidatan superimposed on the world imagery map from the ArcMap software. (a) Seasonal deformation map. (b) Google earth images of Region A. (c) Google earth images of Region B.

\subsubsection{Braided Stream Plains and Salt Lake}

The Chumaer River, which is the northern source of the Yangtze River, flows through the Hoh Xil region. Figure 13a shows that the range of the seasonal deformation is between -50.0 and $10 \mathrm{~mm}$ in the Hoh Xil area. Larger seasonal displacements are observed along the braided stream plains of Chumaer river and around Salt Lake (see Figure 13b). Some studies demonstrate the Salt Lake has started to expand significantly since 2011, and it confronts the rapidly accelerating degradation of permafrost [45]. 


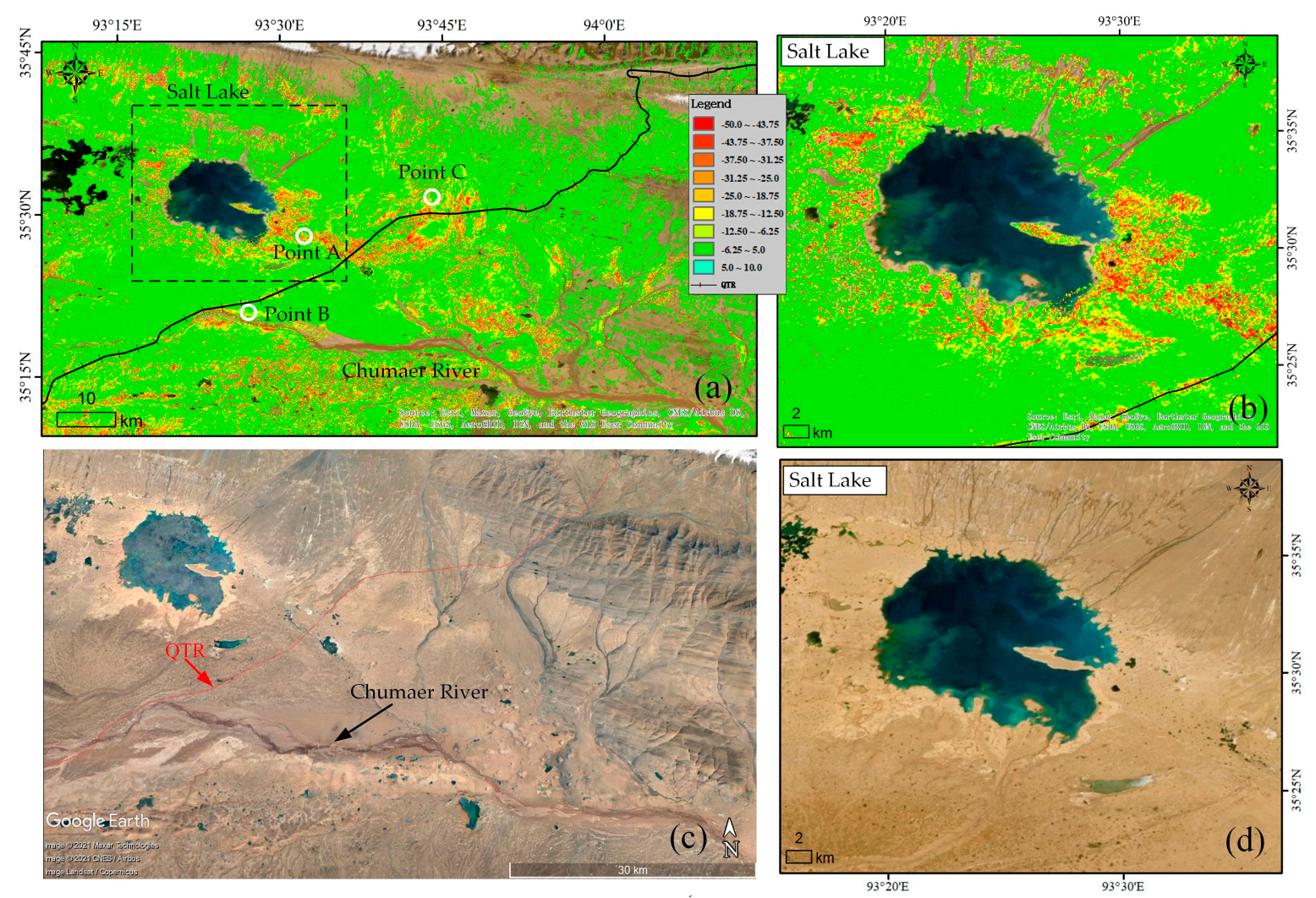

Figure 13. Deformation results superimposed on the world imagery map from the ArcMap software in the Hoh Xil area. (a) Seasonal deformation map. (b) A magnified view of Salt Lake in (a). (c) Google earth images of the Hoh Xil area. (d) Optical images of Salt Lake.

The daily air temperature ( $2 \mathrm{~m}$ surface) of the ERA5 monthly averaged reanalysis product and time series deformations over 16 March 2017-24 March 2020 (reference to 16 March 2017) are presented in Figure 14. The ERA5 product can be downloaded from the ERA-5 repository of European Centre for Medium-Range Weather Forecasts [72]. Figure 14 shows that there are the time lags between the InSAR-observed displacement of the different points and the daily air temperature data. In addition, the thawing period (TP) and freezing period (FP) of each point are calculated according to the time series deformation and the temperature curves. Point A is located around Salt Lake, as shown in Figure 13d, and the range of the time series deformation is between -48.7 and $8.46 \mathrm{~mm}$ (see Figure 14b). From 2017 to 2020, the annual subsidence is $12 \mathrm{~mm}$. Although the annual subsidence gradually decreased, the settlement trend is obvious. The thawing rate was faster in July and August, and the deformation reached its maximum at the end of August, with amplitudes up to $20 \mathrm{~mm}$. It can be seen from the deformation curve that Salt Lake may continue in subsidence in the future, which may be caused by the degradation of permafrost to seasonal permafrost. With the permafrost around the Salt Lake showing a trend of degradation [73], the QTR, which is $8 \mathrm{~km}$ from Salt Lake, may be seriously threatened. In the braided stream plains of Chumaer river, the lower stream power of silt and fine sand transport is small, and they can retain water in the pores due to their highest susceptibilities to ice lens and frost heave. Therefore, in the braided Chumaer River plain (Point B) with a higher soil moisture, the displacement ranges from -20.38 to $14.94 \mathrm{~mm}$ (see Figure 14c,d). Figure 14e,f show that there is a delay of more than one month between the amplitude of deformation during the freeze-thaw cycle and the maximum/minimum values of temperature in the Hoh Xil (point C) area, and the deformation ranges from -26.5 to $24.6 \mathrm{~mm}$. 

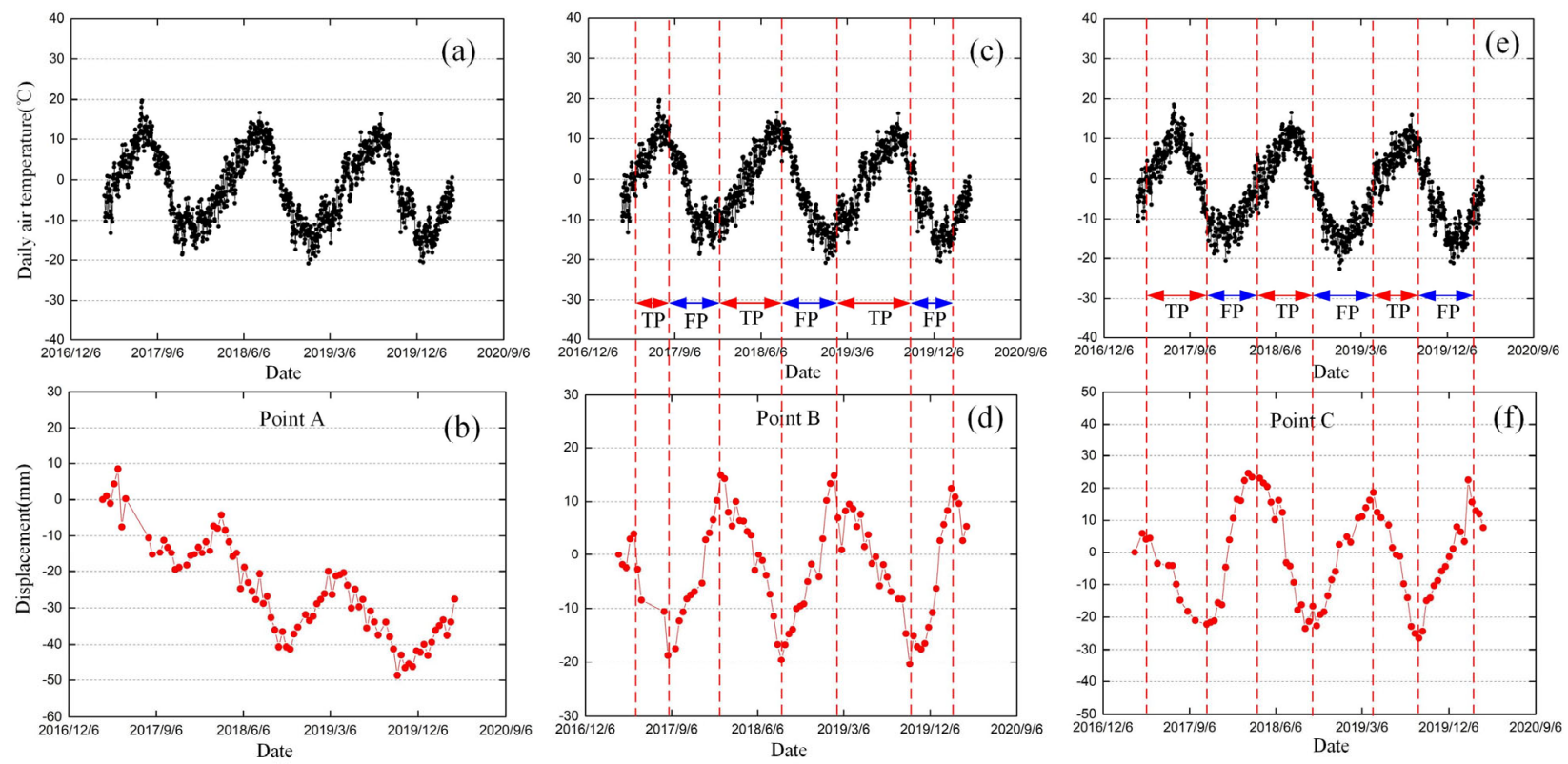

Figure 14. The time series deformation and the ERA5 daily air temperature of extract point. Point A (a), Point B (c), Point C (e) are the daily air temperature. Point A (b), Point B (d), Point C (f) are the ERA5 product.

\subsubsection{Wudaoliang to Wuli}

The seasonal deformation of the Wudaolang- Wuli section of the QTR ranges from -50.0 to $10.0 \mathrm{~mm}$, and the linear deformation rate ranges from -30.0 to $15.0 \mathrm{~mm} / \mathrm{yr}$ (see Figure 15a,b). The deformation rate of Point A ranges from -9.7 to $12.0 \mathrm{~mm} / \mathrm{yr}$ in Wudaoliang area, which is consistent with previous research results [74]. Figure 16a,e show that the range of the time series deformation of Point A is between 39.19 and $27.12 \mathrm{~mm}$. The thawing period starts from the end of March to the beginning of April every year, and the thawing deformation reaches $23.2 \mathrm{~mm}$ at the end of August. Precipitation in the Wudaoliang area is also mainly concentrated from July to August, and the influence of the atmospheric troposphere may lead to a higher result. The freezing period begins at the end of September every year, and the freezing rate increases from October to November, with the amount of freezing reaching up to $17 \mathrm{~mm}$. Figure $16 \mathrm{~b}, \mathrm{f}$ show that serious surface deformation has occurred in the Beiluhe area, with amplitudes up to $40 \mathrm{~mm}$ in recent years [24], and the deformation rate in this area ranges from -10 to $14 \mathrm{~mm} / \mathrm{yr}[41,75]$. The field investigation photos in September 2020 showed some subsidence zones along the QTR subgrade, and there was a large amount of water in some areas (Figure 17). The Fenghuo Mountain region (Point $\mathrm{C}$ ) is located to the southeast of Hoh Xil with a deformation range of -29.43-27.13 mm during March 2017-March 2020. Figure 16c,g show that the thawing period in this region begins in mid-April each year, and the displacement reaches its maximum at the end of September. The freezing period begins in early October each year, and ends in late March of the following year. The Wuli area (Point D) is located in the upper reaches of Tuotuhe. The displacement range is between -29.43 and $27.13 \mathrm{~mm}$. The thawing period in this region begins from early October to early April each year. The thawing rate is faster in July to August, with $10 \mathrm{~mm}$ cumulative deformation. 

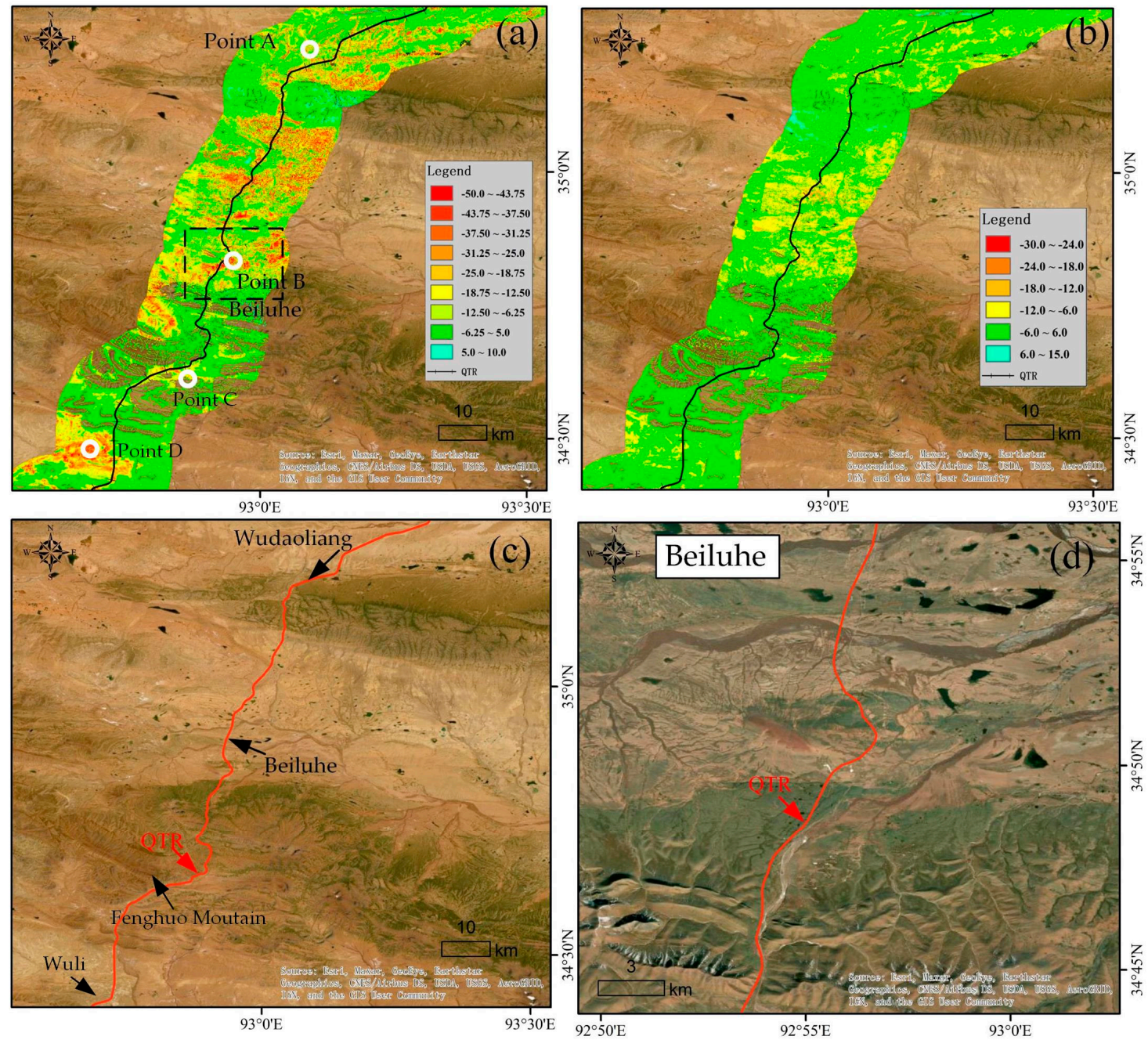

Figure 15. Deformation results superimposed on the world imagery map from the ArcMap software from Wudaoliang to Wuli. (a) Seasonal deformation map. (b) Deformation rate map. (c) Optical images. (d) Optical images for Beiluhe.
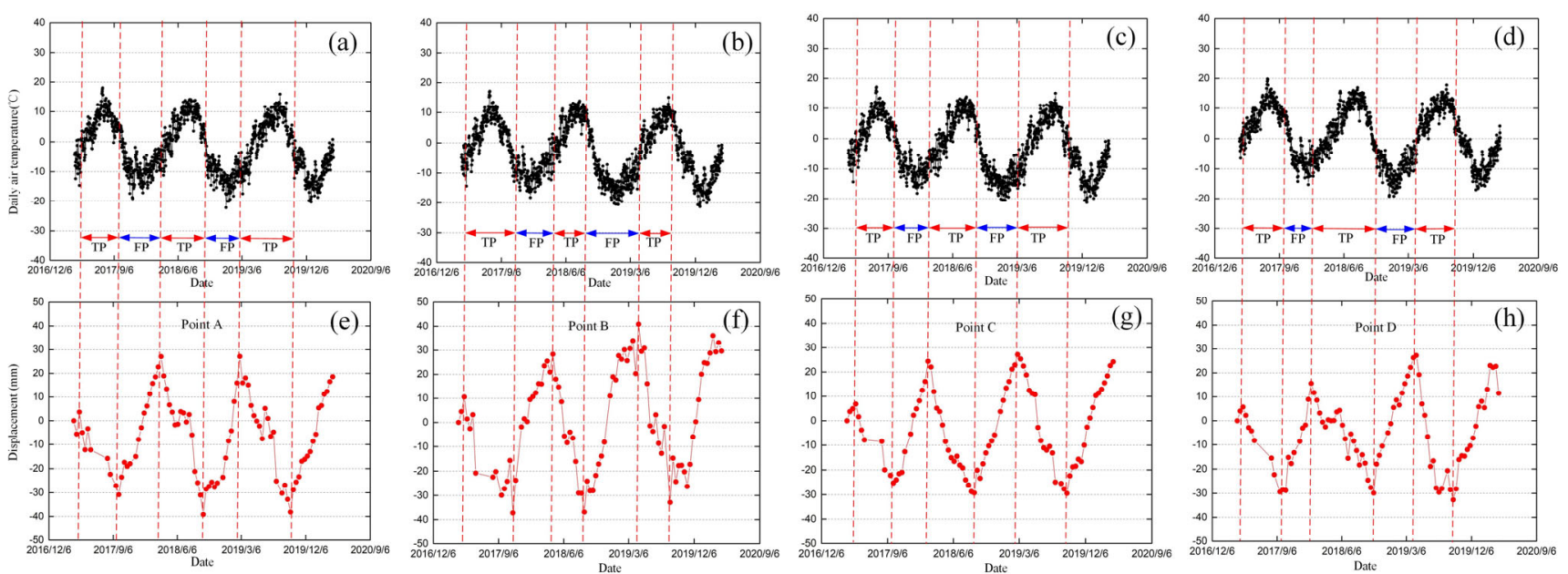

Figure 16. The time series deformation and the ERA5 daily air temperature of extract point. Point A (a), Point B (c), Point C (e), Point D (g) are the daily air temperature. Point A (b), Point B (d), Point C (f), Point D (h) are the ERA5 product. 


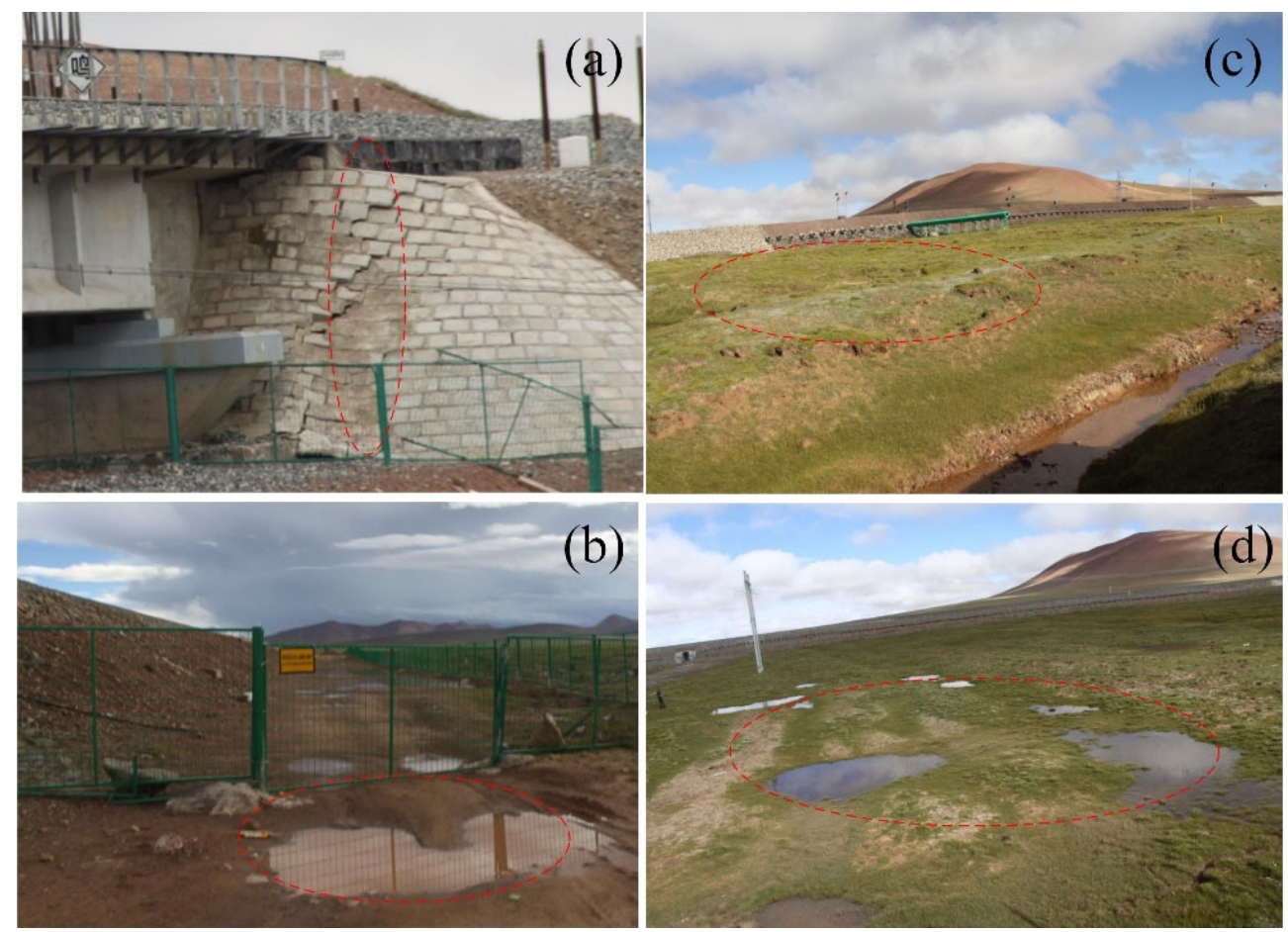

Figure 17. Field investigate photos in Beiluhe area. (a) QTR embankment. (b) Subsidence areas along the QTR. (c) The cut slope of the QTR. (d) Alpine meadow area.

\subsubsection{Naqu to Lhasa}

The deformation result map of the Naqu to Lhasa section of the QTR area is shown in Figure 18. The seasonal deformation of the Naqu to Damxung section ranges from -25.0 to $10.0 \mathrm{~mm}$, and the deformation rate ranged from -15.0 to $15.0 \mathrm{~mm} / \mathrm{yr}$. Figure $19 \mathrm{a}, \mathrm{b}$ show that the time series displacement of Naqu (Point A) ranges from -15.76 to $15.88 \mathrm{~mm}$. Damxung (Point B) is located in the vicinity of the bull, with a time-series displacement ranging from -16.23 to $14.59 \mathrm{~mm}$ (Figure 19c,d). At the end of August each year, the subsidence reached its maximum, and the annual average deformation rate was $-12.0 \mathrm{~mm} / \mathrm{yr}$, which was consistent with a previous study in which the maximum subsidence rate after railway construction was $-10 \mathrm{~mm} / \mathrm{yr}$ in 2007 [12]. The seasonal deformation of the Yangbajing to Lhasa section of the QTR area ranges from -18.75 to $-6.25 \mathrm{~mm}$. Figure $19 \mathrm{f}$ shows that the time series deformation range is between -27.0 and $20 \mathrm{~mm}$ in the Yangbajing area (Point C), which has an average altitude of $4300 \mathrm{~m}$, and the mountains on both sides of the basin range from 5000 to $6000 \mathrm{~m}$. Glaciers and various geothermal fields are developed in this region, thus the high deformation trend is observed on the surface. Figure 18b shows that the deformation rate in the Lhasa area (Point D) is relatively small, with a range of $-4.0-6.0 \mathrm{~mm} / \mathrm{yr}$, while the seasonal deformation ranges from -31.25 to $-12.50 \mathrm{~mm}$. Seasonal deformation shows the dynamic change of the ALT, and the Lhasa area is located in the seasonally frozen ground areas, so the seasonal deformation values are high. The QTR is far away from the deformation area, so it has little influence on the railway. Furthermore, Figure 18d shows that some braided rivers are distributed in the southern region of Lhasa with the higher soil moisture, leading to high deformation in this region. 

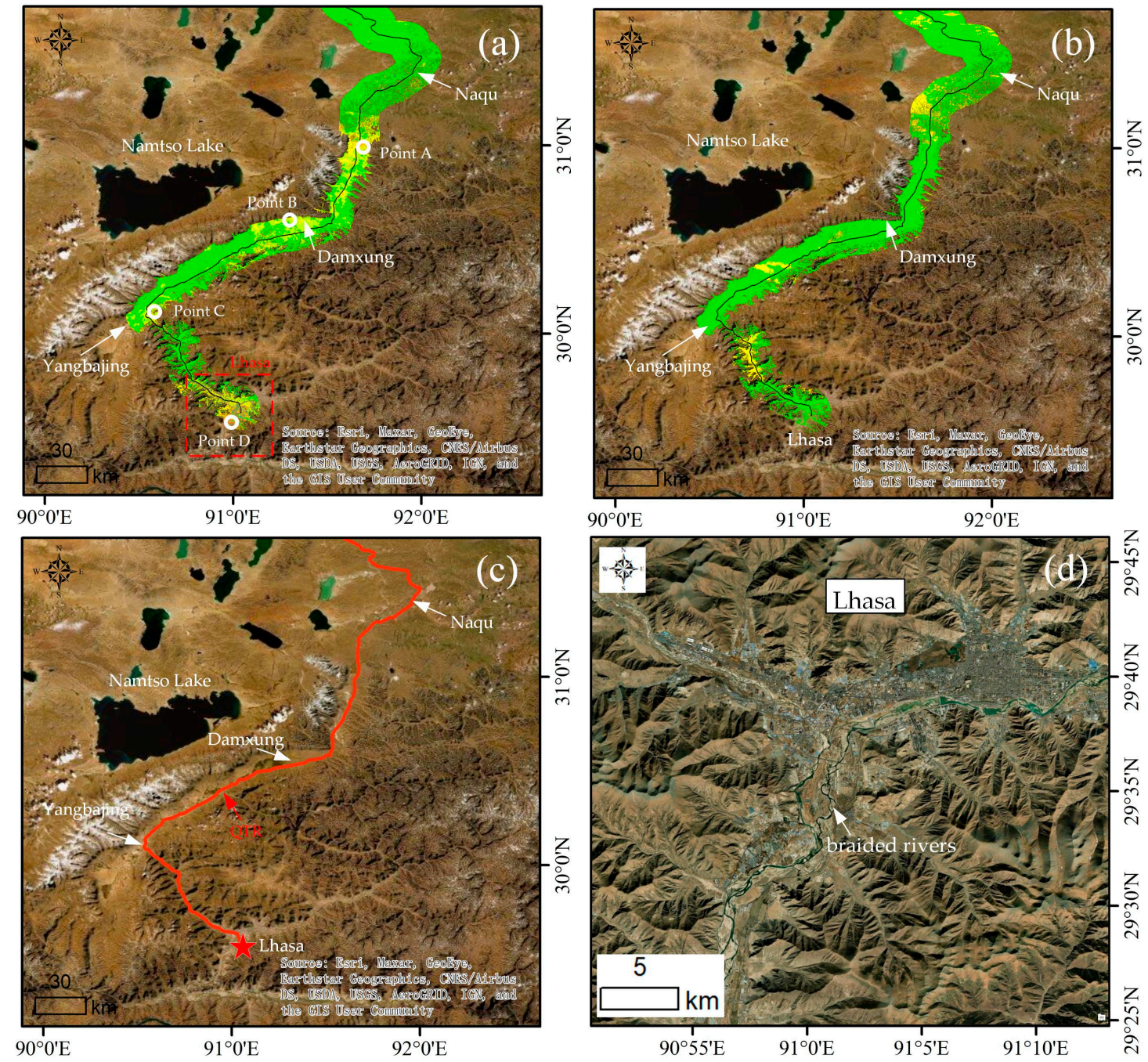

Figure 18. Deformation results superimposed on the world imagery map from the ArcMap software from Naqu to Lhasa. (a) Seasonal deformation map. (b) Deformation rate map. (c) Optical images. (d) Optical images for Lhasa.
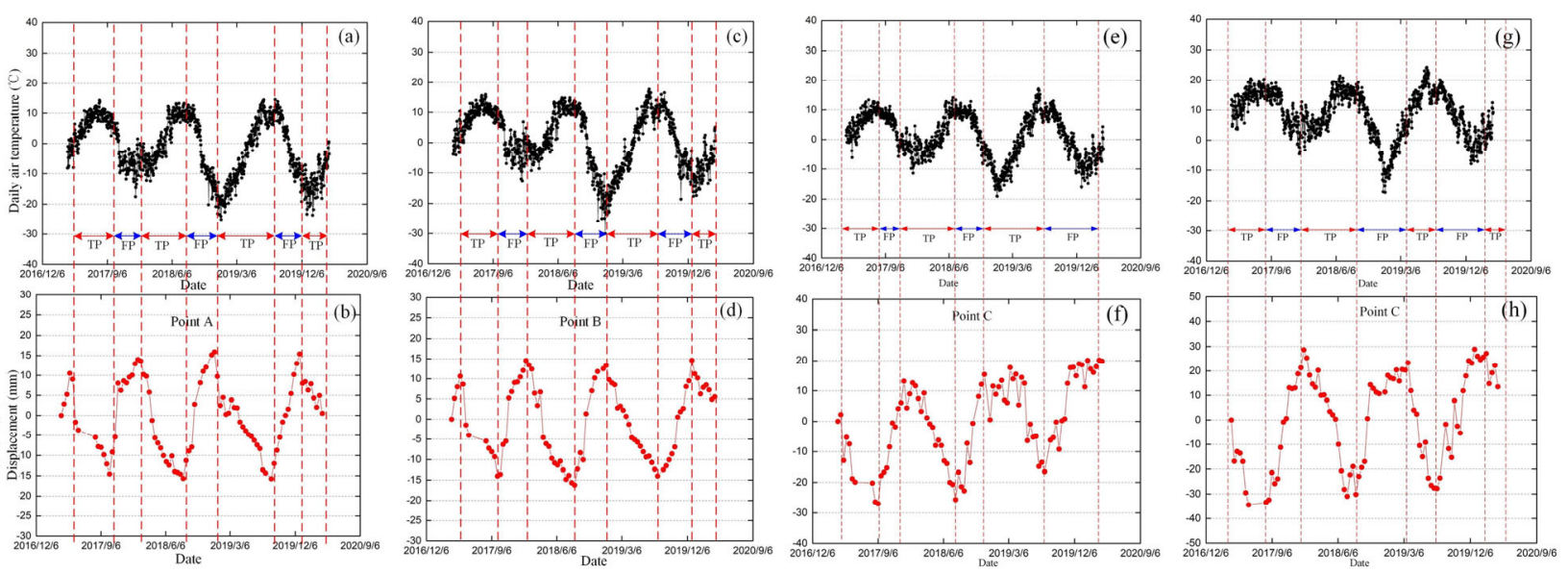

Figure 19. The time series deformation and the ERA5 daily air temperature of extract point. Point A (a), Point B (c), Point C (e), Point D (g) are the daily air temperature. Point A (b), Point B (d), Point C (f), Point D (h) are the ERA5 product. 


\subsection{Permafrost Distribution Map along the QTR}

Based on the InSAR time series deformation results, the permafrost distribution map is obtained by using the ISODATA classification method, which is compared to the permafrost classification map of 2017 on the QTP from the National Tibetan Plateau Data Center [53,75], shown in Figure 20. The results show that the classification results of Zou's method are mostly consistent with those of InSAR method. However, there are some differences in the red circle regions in Figure 20b. Seasonally frozen ground areas in red circled regions are relatively small. The following are possible reasons for this: the InSAR method is based on the deformation law of frozen soil, and it reflects the actual time series deformation of frozen soil without other input data, while Zou's method employs ground observations and soil investigated datasets based on TTOP model to estimate permafrost distribution. In addition, there are bias or errors of time series deformation estimation using the MTS-InSAR method.
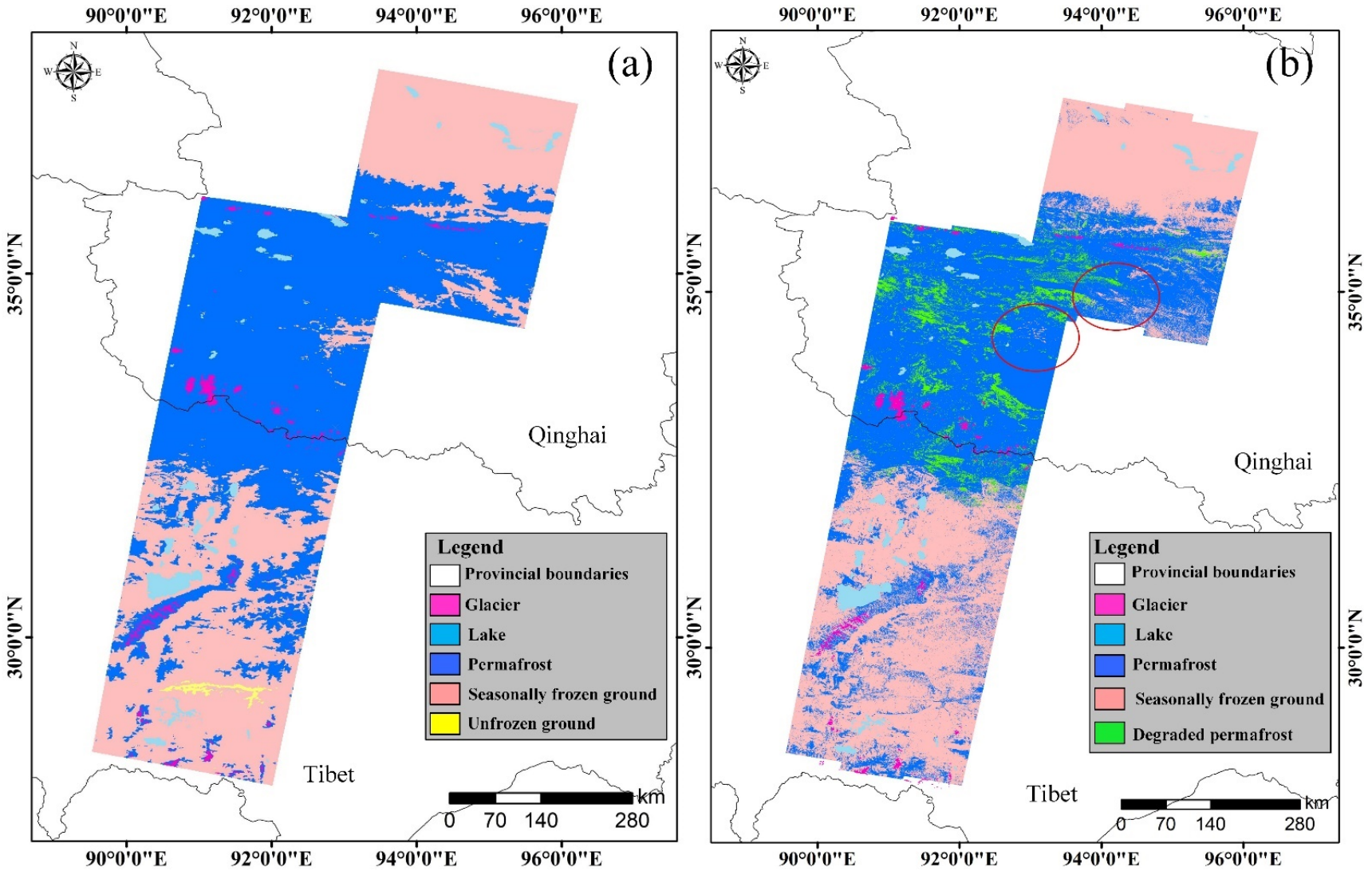

Figure 20. Comparison of frozen soil classification results between the InSAR method based on the InSAR time series deformation and (a) Zou's method. (b) InSAR method.

InSAR can detect the deformation law of some permafrost areas, which are characterized by the seasonal oscillation and the increasing interannual settlement year by year. Therefore, the permafrost areas are divided into degraded permafrost, and stable permafrost areas with the same seasonal deformation trend. Few permafrost areas have been classified as seasonally frozen ground in recent years, due to the deterioration of permafrost.

The deformation curve of seasonally frozen ground is shown in Figure 21a,b. It can be found that the positive or negative seasonal amplitude of seasonally frozen ground is similar. In other words, the seasonal freezing uplift are almost the same as the thawing subsidence of permafrost. The annual deformation trend is stable. Due to the different of active layer thickness, the amplitude of seasonal deformation is different in different regions. The deformation law of permafrost is complex. It may show irregular annual 
increase year by year, namely uplift (Figure 21d), or irregular annual decline (Figure 21e). Such kind of deformation trends may exist in rock glaciers or high-altitude mountains. The annual subsidence shows a regular increasing trend year by year, which is classified as degraded permafrost (Figure 21c).
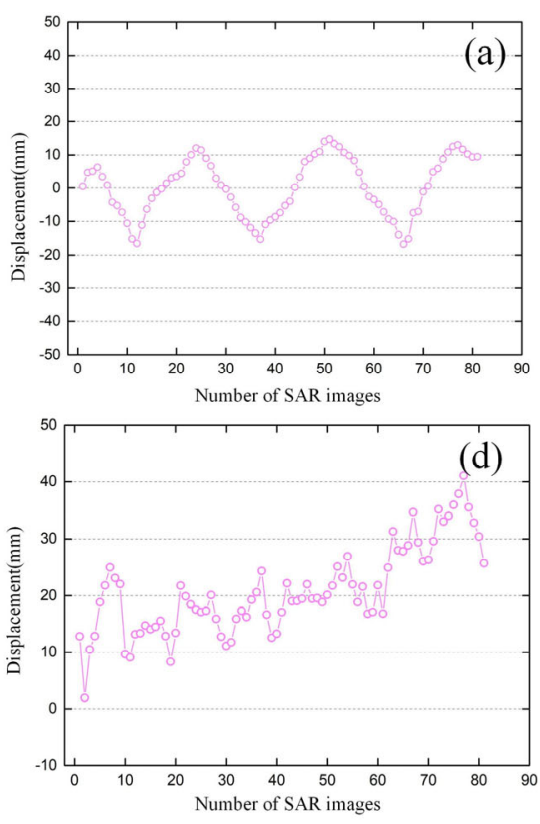

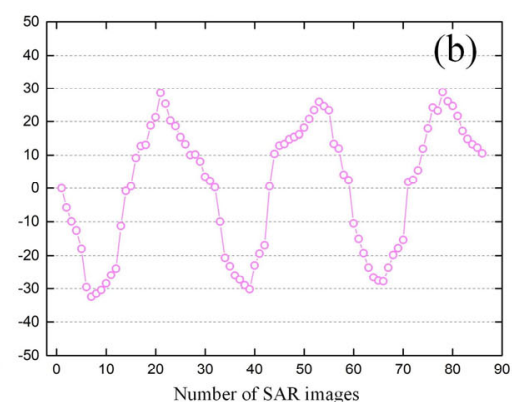

(b)
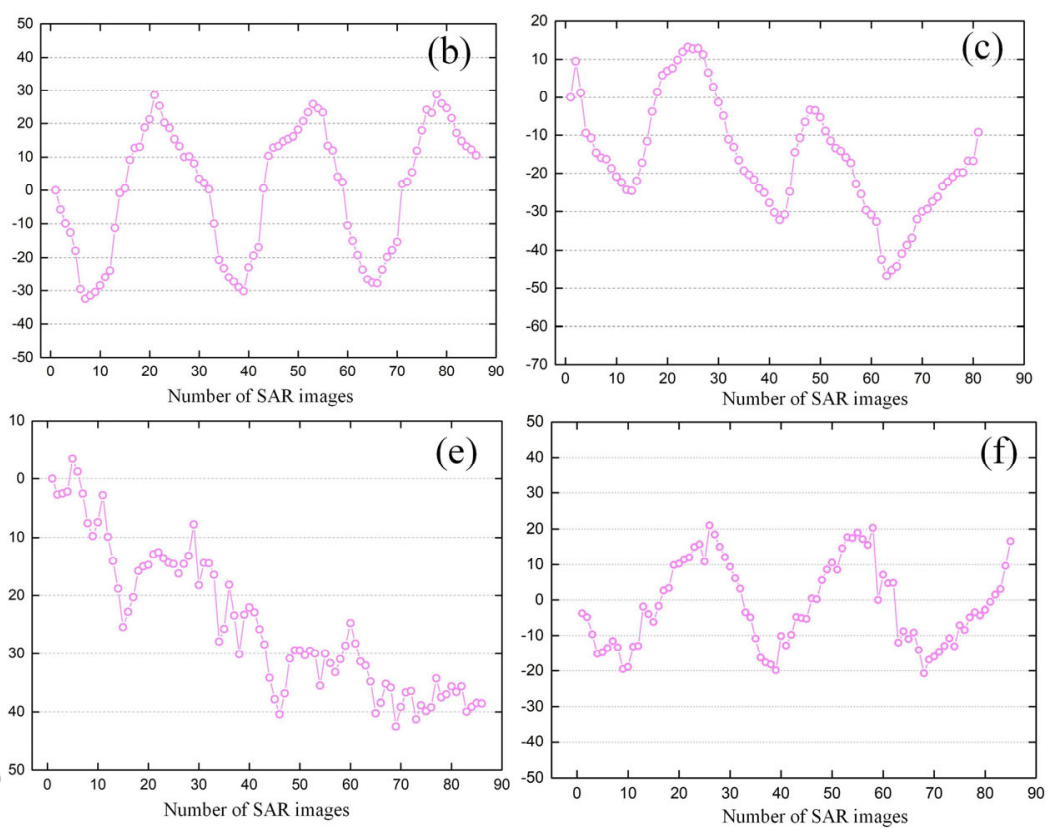

Figure 21. Deformation graphs of the frozen soil. $(\mathbf{a}, \mathbf{b})$ are the deformation curve of seasonally frozen ground. (c) is the deformation curve of degraded permafrost. $(\mathbf{d}-\mathbf{f})$ are the deformation curve of permafrost.

It should be noted that seasonal freezing-thawing processes may also occur in some permafrost areas with temperature change, and the deformation law of permafrost accords with that of seasonally frozen ground due to the different of active layer thickness (Figure 21f). For this kind of permafrost, the permafrost classification results of Zou's method are adopted as prior knowledge in this study, and the seasonally frozen ground areas are first separated, then the rest of the frozen soil areas are classified again according to the annual average deformation rate. If the annual average deformation rate of some permafrost areas ranges from -20 to $20 \mathrm{~mm} / \mathrm{yr}$, it is classified as seasonally frozen ground, otherwise, these areas are classified as permafrost.

\subsection{Validation of the InSAR Results}

To evaluate the accuracy of the InSAR results in this paper, leveling data from other researchers were used for verification in some sections of the QTR $[76,77]$. The geographical locations of seven leveling points along the QTR passing through the Wudaoliang, Beiluhe and Tuotuohe areas are shown in Figure 22. The deformation results of 4 January 2018, and 9 February 2018, were extracted by using Frame 475 of Track 150 Sentinel data. Then, the leveling results were converted to the displacement of LOS direction based on the incident angle. Finally, they could be compared with the A, B, and C leveling points (see Table 2). Table 2 shows that the absolute errors of the leveling data and InSAR measurements at points $\mathrm{A}, \mathrm{B}$ and $\mathrm{C}$ were $2.3,3.3$ and $2.9 \mathrm{~mm}$, respectively, which were relatively small. 


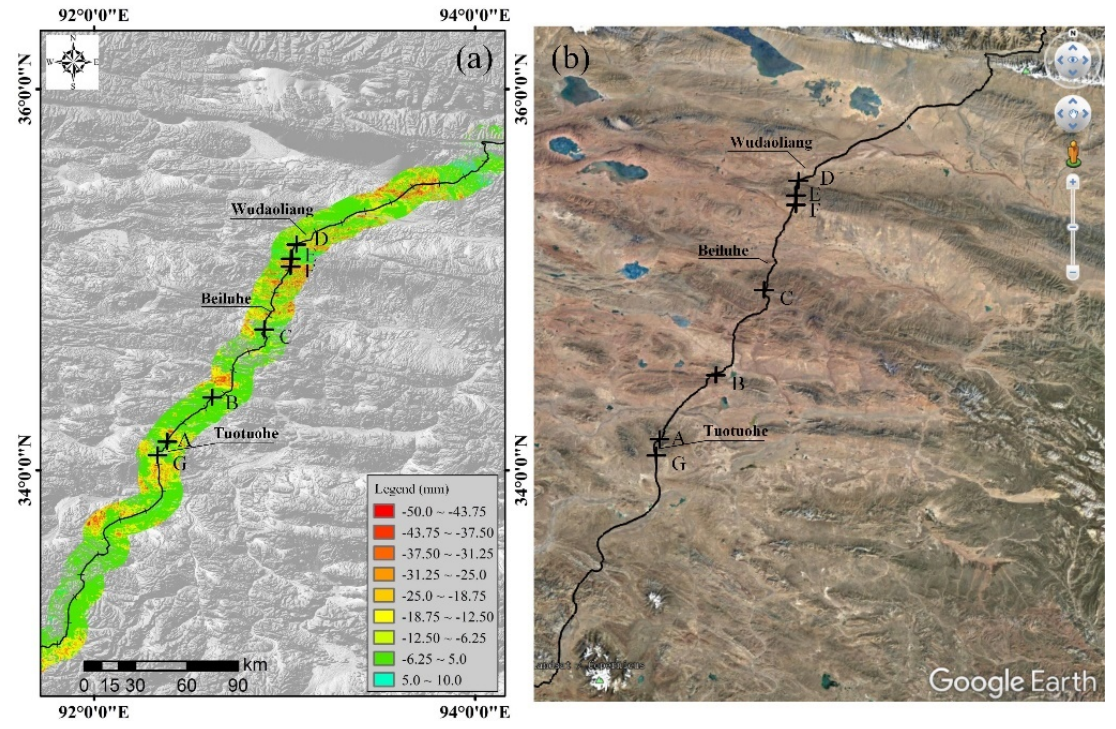

Figure 22. Geographic location map of leveling points along the QTR. (a) The seasonal deformation map. (b) The Google Earth imagery.

Table 2. The absolute error between the measured values of leveling points $A, B$, and $C$ and the InSAR observed values along the QTR.

\begin{tabular}{cccc}
\hline Benchmark & A & B & C \\
\hline Leveling(unit:mm) & 2.2 & -8.8 & -16.6 \\
InSAR results(unit:mm) & 4.5 & -12.1 & -19.5 \\
Absolute error(unit:mm) & 2.3 & 3.3 & 2.9 \\
\hline
\end{tabular}

Meanwhile, time series InSAR deformation at the corresponding positions of the four leveling points $\mathrm{D}, \mathrm{E}, \mathrm{F}$, and $\mathrm{G}$ were extracted for comparative verification, as shown in Figure 23. The absolute errors between the four leveling points and the InSAR results were $0.1-3.4 \mathrm{~mm}, 0.25-4.62 \mathrm{~mm}, 0.19-4.23 \mathrm{~mm}$, and $0.14-3.28 \mathrm{~mm}$, respectively. The correlations between D, E, F, G, and InSAR were 0.98, 0.91, 0.92, and 0.93, respectively.
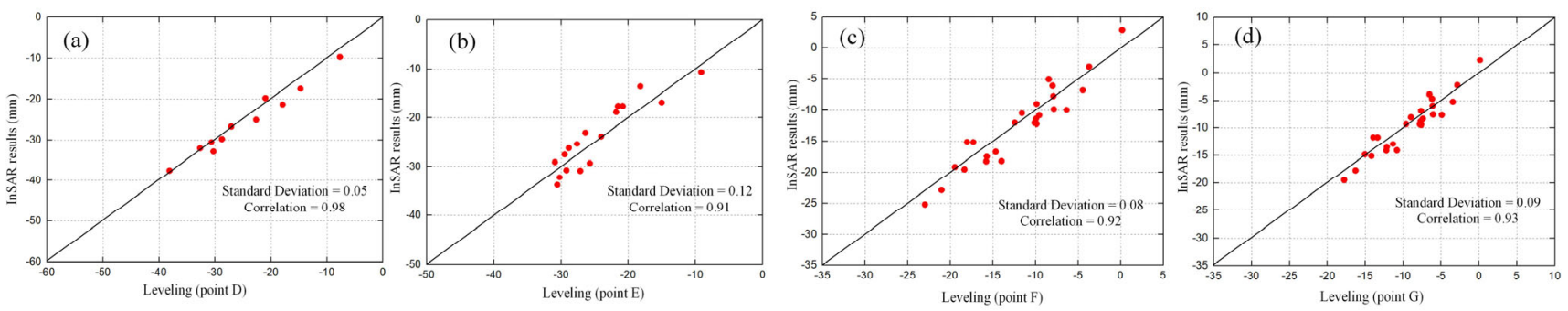

Figure 23. Correlation between leveling and InSAR measurements at points D, E, F, and G. (a) Point D. (b) Point E. (c) Point F. (d) Point G.

\section{Discussion}

\subsection{Comparison with Other Permafrost Deformation Studies along the QTR}

To assess the deformation results along the QTR, the comparison among other findings that are shown in Table 3. Chen et al. [27] observed deformation rates of $-20-20 \mathrm{~mm} / \mathrm{yr}$ from 2007 to 2010. Chen et al. [22] reported that the QTR and its neighborhood experienced more obvious surface subsidence than surrounding features with a range of -25 to $-10 \mathrm{~mm} / \mathrm{yr}$. Chang et al. [21] found seasonal displacements of over $15 \mathrm{~mm}$, and inhomogeneous deformation along the track during 2007-2009. Wang et al. [39] collected TerraSAR-X ascending images from June 2014 to December 2015, and showed that the 
seasonal displacement of the QTR ranged from 20 to $90 \mathrm{~mm}$. The amplitude of seasonal deformation in the Beiluhe area ranged from $-50 \mathrm{~mm}$ to $10 \mathrm{~mm}$, using our composite index model. Zhang et al. [45] obtained the Naqu-Lhasa section deformation results of the Qinghai-Tibet Railway from 2003 to 2012, using the full rank matrix SBAS method. Zhang et al. [17] used multisource SAR images to retrieve the Wudaoliang-Tuotuohe section deformation rate, which ranged from -20 to $10 \mathrm{~mm}$ /year, and most of the QTR appeared to be stable. Han et al. [46] adopted the StaMPS-InSAR method to detect ground displacements ranging from -12.80 to $7.20 \mathrm{~mm}$ without any a priori deformation models from March 2017 to June 2018. Recently, Li et al. [78] processed Envisat ASAR data from 2006 to 2009 in Wudaoliang, using SBAS-InSAR technique, with the result of the LOS deformation rate ranging from -15 to $15 \mathrm{~mm} / \mathrm{yr}$. The LOS deformation rate with a value range of -20 to $20 \mathrm{~mm} / \mathrm{yr}$ were observed along the QTR in this study. This result is consistent with the above studies.

Table 3. Permafrost deformation studies along the QTR.

\begin{tabular}{|c|c|c|c|c|c|}
\hline Study Area & InSAR Method & SAR Dataset & $\begin{array}{l}\text { Observation } \\
\text { Period }\end{array}$ & $\begin{array}{c}\text { Seasonal } \\
\text { Displacements or } \\
\text { Deformation Rate }\end{array}$ & Authors \\
\hline $\begin{array}{c}\text { Beiluhe- } \\
\text { Fenghuoshan }\end{array}$ & IPTA & $\begin{array}{c}\text { ALOS-1 PALSAR } \\
\text { and Envisat ASAR }\end{array}$ & 2007-2010 & $-20-20 \mathrm{~mm} / \mathrm{yr}$ & Chen et al. (2012) \\
\hline $\begin{array}{c}\text { Beiluhe- } \\
\text { Fenghuoshan }\end{array}$ & SBAS & ALOS-1 PALSAR & 2007-2010 & $-25-10 \mathrm{~mm} / \mathrm{yr}$ & Chen et al. (2013) \\
\hline Qiangtang terrane & MTInSAR & Envisat ASAR & 2007-2009 & $-15-15 \mathrm{~mm}$ & Chang et al. (2015) \\
\hline Beiluhe & MTInSAR & TerraSAR-X & 2014-2015 & $20-90 \mathrm{~mm}$ & Wang et al. (2017) \\
\hline Naqu-Lhasa & SBAS & $\begin{array}{c}\text { Envisat ASAR and } \\
\text { TerraSAR-X }\end{array}$ & 2003-2012 & $-20-20 \mathrm{~mm} / \mathrm{yr}$ & Zhang et al. (2018) \\
\hline $\begin{array}{l}\text { Wudaoliang- } \\
\text { Tuotuohe }\end{array}$ & MT-InSAR & $\begin{array}{c}\text { Sentinel-1/Envisat } \\
\text { ASAR/ERS-1 }\end{array}$ & 1997-2018 & $-20-10 \mathrm{~mm} / \mathrm{yr}$ & Zhang et al. (2019) \\
\hline Wudaoliang & StaMPS-InSAR & $\begin{array}{c}\text { Sentinel-1 and } \\
\text { TerraSAR-X }\end{array}$ & 2017-2018 & $\begin{array}{c}-12.80-7.20 \\
\mathrm{~mm} / \mathrm{yr}\end{array}$ & Han et al. (2020) \\
\hline Wudaoliang & SBAS & Envisat ASAR & 2006-2009 & $\begin{array}{c}0-40 \mathrm{~mm} /-15-15 \\
\mathrm{~mm} / \mathrm{yr}\end{array}$ & Li et al. (2021) \\
\hline Golmud-Lhasa & NSBAS & Sentinel-1 & 2017-2020 & $-20-20 \mathrm{~mm} / \mathrm{yr}$ & This study \\
\hline
\end{tabular}

\subsection{Advantages and Limitations of Permafrost Distribution Mapping}

The InSAR method of permafrost distribution mapping is based on the real deformation law of the frozen soil, and the classification results reflect the surface deformation trend of different types of frozen soil. The ISODATA classification method is unsupervised, and the deformation law of permafrost is unknown in advance. The permafrost distribution mapping of the InSAR method is based on all kinds of frozen soil deformation curves, without temperature, annual average ground temperature, soil moisture, altitude, soil type, and other factors, and without the establishment of physical and empirical models of permafrost. It reduces the computation and complexity of permafrost classification. Therefore, it can be used as a new method for mapping permafrost distribution. Zou's method employs the TTOP model to simulate permafrost distribution, based on measured data, and it needs many input parameters. The resolution of InSAR results in this experiment is approximately $60 \mathrm{~m}$, so the spatial resolution of permafrost distribution map based on InSAR time series deformation is higher. Permafrost degradation is one of the most important problems in cryopedology, at present. This study divides some permafrost regions with decreasing annual deformation into degraded permafrost, which provides a new insight and theoretical basis for the study of permafrost degradation.

However, there are the following limitations in this study:

(1) The deformation law of permafrost is complex, the deformation laws of some permafrost areas and seasonally frozen ground are similar. 
To explain the deformation law of permafrost in more detail, the schematic diagram of the thawing process of permafrost is shown in Figure 24. The permafrost is mainly divided into two layers: the active layer is the first layer, and the permafrost is the second layer. Seasonal thawing subsidence and frost heaving occur in the upper layer of permafrost, that is, the active layer, which generally melts from April to September, and freezes from October to March. However, seasonally frozen ground has only active layer, which also experiences the seasonal freezing-thawing cycle, and completely melts in the thawing period. It is assumed that there is no water loss in the active layer during the freezingthawing cycle of frozen soil, and the surface subsidence is completely caused by the change of ice to water in the active layer. During the freezing period, if no water is lost and no other surface runoff is mixed with the water, the water is completely converted to ice. Therefore, the surface deformation presents periodic curve of freezing uplift and thawing subsidence. Seasonally frozen ground will show a seasonal freezing-thawing cycle, the deformation amplitude is similar, and the deformation of permafrost will also appear like the deformation curve of seasonally frozen ground. Therefore, seasonally frozen ground based on some permafrost distribution results of the Zou's method and annual average deformation rate is distinguished.
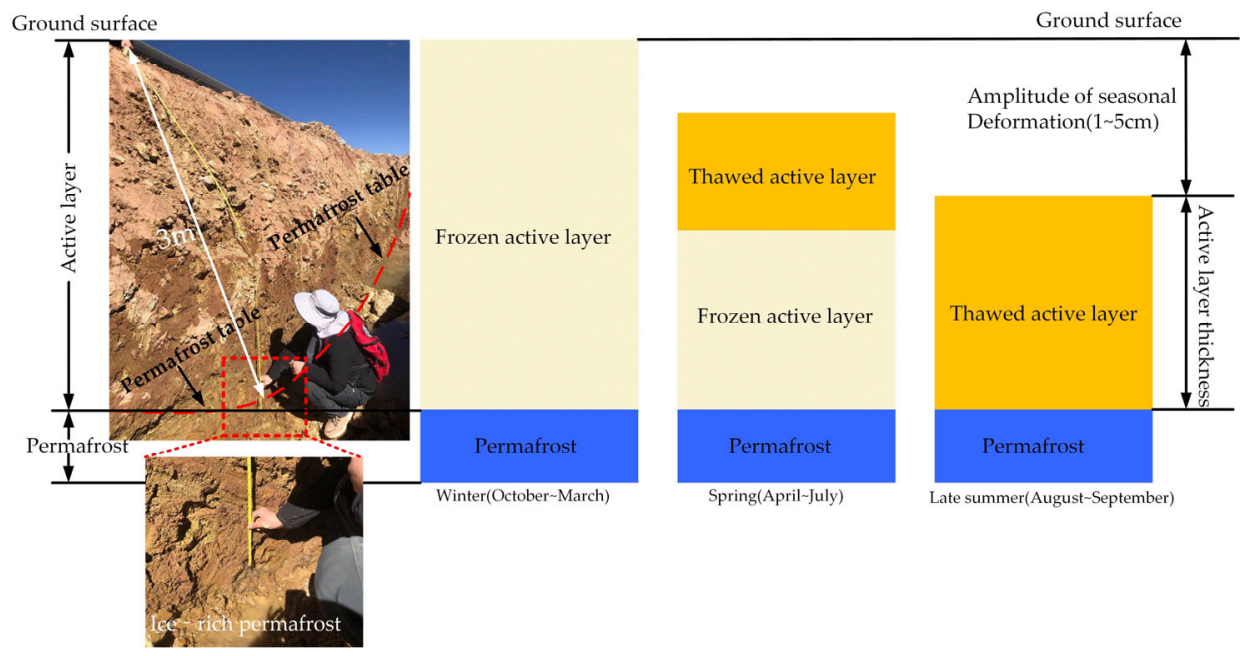

Figure 24. Schematic diagram of permafrost during thawing period.

(2) Unfortunately, the deformation law of unfrozen ground cannot be distinguished.

(3) There are some errors in the calculation process of InSAR method, such as unwrapping phase errors, residual topographic phase errors, and residual atmospheric phase errors, etc. These errors may lead to the incorrect time series deformation results which are related to permafrost distribution.

(4) Without combining other measured data, only time series deformation is used as the input data, and the classification basis is relatively simple.

\section{Conclusions}

In this paper, the large-scale seasonal deformation and annual average deformation rate maps (approximately $3.15 \times 10^{5} \mathrm{~km}^{2}$ ), using the MTS-InSAR method, were obtained along the QTR, which can be used to analyze the seasonal displacement of freeze-thaw cycles and investigate sections of the QTR with potential geohazards. The seasonal deformation and the long-term displacements based on a composite index model were analyzed. The following conclusions can be drawn:

The seasonal amplitude in the study area ranged from -70 to $20 \mathrm{~mm}$, and was generally smaller than $30 \mathrm{~mm}$ in most areas from 16 March 2017 to 24 March 2020. The LOS deformation rate ranged from -40 to $20 \mathrm{~mm} / \mathrm{yr}$, and was generally smaller than $16 \mathrm{~mm} / \mathrm{yr}$ in most areas, and the secular subsidence trend was small. The higher values of seasonal deformation were mainly distributed on the glacier outwash plains of the Kunlun 
Mountains, located near Salt Lake, the Beiluhe areas, the braided stream plains of Tuotuohe, and downstream of the Chumar River, the Yangbajing area, and the southern region of Lhasa.

The seasonal deformation range of the $10 \mathrm{~km}$ buffer zone along the QTR was $-50-10 \mathrm{~mm}$, and the LOS deformation rate ranged from -30 to $15 \mathrm{~mm} / \mathrm{yr}$. Compared with the leveling data, the absolute error between the leveling points and the InSAR measurements was low, and the correlations were $0.98,0.91,0.92$, and 0.93 , respectively. The sections with high deformation of the subsidence area were mainly distributed on Golmud-Xidatan, Budongquan-Hoh Xili, Wudaoliang-Beiluhe, Fenghuo Mountain -Wuli, TuotuoheYanshiping, Tanggula Mountain-Amdo, Naqu-Damxung, and Yangbajing-Lhasa. The whole railway was relatively stable. The amplitude of the seasonal deformation of the railway ranged from -30 to $15 \mathrm{~mm}$. The LOS deformation rate ranged from -20 to $20 \mathrm{~mm} / \mathrm{yr}$.

The deformation of the frozen soil area along the Golmud-Xidatan section of the QTR was relatively low, and the Xidatan region with high seasonal deformation was mainly distributed on glacier outwash plains and floodplain regions. The BudongquanHoh Xil sections of the QTR with high seasonal deformation were distributed on the braided stream plains of Chumaer River, Salt Lake, and part of the Hoh Xil region. The degradation of permafrost around Salt Lake may have an impact along the QTR. Serious surface deformation has occurred in the Beiluhe area, with amplitudes of up to $40 \mathrm{~mm}$ in recent years. The QTR embankment may be less threatened by the Tanggula Mountain Pass to the Amdo and Naqu to Lhasa sections of the QTR.

Based on InSAR time series deformation results, a new mapping method for permafrost distribution was proposed along the QTR, which can classify the permafrost as permafrost, seasonally frozen ground, and degraded permafrost. The permafrost distribution map of InSAR method and Zou's method were almost similar in most areas, and the classification of seasonally frozen ground was accurate, while there were differences in fewer areas of permafrost. Our method provides new insights for permafrost distribution mapping.

In the future work, multisource SAR data will be used to conduct surface deformation survey and retrieve active layer thickness on the QTP at a large scale. Meanwhile, other measurement data, remote sensing data, and InSAR data will be fused to study permafrost distribution.

Author Contributions: Conceptualization, J.W., C.W. and H.Z.; formal analysis, J.W.; methodology, J.W. and Y.T.; software, J.W., Y.T., W.D. and L.D.; validation, J.W., C.W. and L.D.; writing—original draft, J.W.; writing —review \& editing, C.W. and H.Z.; visualization, J.W.; supervision, C.W.; project administration, H.Z.; funding acquisition, C.W. All authors have read and agreed to the published version of the manuscript.

Funding: This research was supported by the Strategic Priority Research Program of the Chinese Academy of Sciences, Grant No. XDA19090126 and the National Natural Science Foundation of China, Grant No. 41930110.

Institutional Review Board Statement: Not applicable.

Informed Consent Statement: Not applicable.

Data Availability Statement: Sentinel-1 data is provided by the European Space Agency (ESA) and available from the Alaska Satellite Facility (ASF) (https://vertex.daac.asf.alaska.edu, accessed on 19 November 2021). SRTM DEM data is available at https://srtm.csi.cgiar.org/srtmdata/, accessed on 19 November 2021. ERA5- daily air temperature is available at https://cds.climate.copernicus.eu/ cdsapp\#!/home, accessed on 19 November 2021. The permafrost distribution data set is provided by National Tibetan Plateau Data Center (http:/ / data.tpdc.ac.cn, accessed on 19 November 2021).

Acknowledgments: The authors would like to thank the EU Copernicus Program for providing the Sentinel-1A SAR data, and NASA and CGIAR-CSI for providing SRTM DEM data. The authors wish to thank GIAnT toolbox for providing the InSAR and Time-series analysis tools. Special thanks go to National Tibetan Plateau Data Center (http:/ / data.tpdc.ac.cn, accessed on 19 November 2021) for providing the new map of permafrost distribution on the Tibetan Plateau (2017). Qingbai Wu 
and Ji Chen and Beiluhe Station of Northwest Institute of Eco-Environment and Resources of CAS are acknowledged for field support. Zhengjia Zhang of China University of Geosciences and Xuefei Zhang of Institute of Tibetan Plateau Research of CAS are acknowledged for helpful discussions.

Conflicts of Interest: The authors declare no conflict of interest.

\section{References}

1. Dobiński, W. International Encyclopedia of Geography: People, the Earth, Environment and Technology. In Permafrost: Definition and Extent; Wiley: Houston, TX, USA, 2016; pp. 1-10.

2. Wang, T.; Wu, T.; Wang, P.; Li, R.; Xie, C.; Zou, D. Spatial distribution and changes of permafrost on the Qinghai-Tibet Plateau revealed by statistical models during the period of 1980 to 2010. Sci. Total Environ. 2019, 650, 661-670. [CrossRef] [PubMed]

3. Cao, B.; Zhang, T.; Wu, Q.; Sheng, Y.; Zhao, L.; Zou, D. Permafrost zonation index map and statistics over the Qinghai-Tibet Plateau based on field evidence. Permafr. Periglac. Process. 2019, 30, 178-194. [CrossRef]

4. Wu, T.; Zhao, L.; Li, R.; Wang, Q.; Xie, C.; Pang, Q. Recent ground surface warming and its effects on permafrost on the central Qinghai-Tibet Plateau. Int. J. Climatol. 2013, 33, 920-930. [CrossRef]

5. Zhao, L.; Wu, T.; Xie, C.; Li, R.; Wu, X.; Yao, J.; Yue, G.; Xiao, Y. Support geoscience research, environmental management, and engineering construction with investigation and monitoring on permafrost in the Qinghai-Tibet Plateau, China. Bull. Chin. Acad. Sci. 2017, 32, 1159-1168.

6. Cheng, G.; Zhao, L.; Li, R.; Wu, X.; Sheng, Y.; Hu, G.; Zou, D.; Jin, H.; Li, X.; Wu, Q. Characteristic, changes and impacts of permafrost on Qinghai-Tibet Plateau. Chin. Sci. Bull. 2019, 64, 2783-2795.

7. Zhao, L.; Wu, Q.; Marchenko, S.; Sharkhuu, N. Thermal state of permafrost and active layer in Central Asia during the International Polar Year. Permafr. Periglac. Process. 2010, 21, 198-207. [CrossRef]

8. Biskaborn, B.K.; Smith, S.L.; Noetzli, J.; Matthes, H.; Vieira, G.; Streletskiy, D.A.; Schoeneich, P.; Romanovsky, V.E.; Lewkowicz, A.G.; Abramov, A. Permafrost is warming at a global scale. Nat. Commun. 2019, 10, 264. [CrossRef]

9. Jin-ping, L.; Yu, S. Analysis of the thermal stability of an embankment under different pavement types in high temperature permafrost regions. Cold Reg. Sci. Technol. 2008, 54, 120-123. [CrossRef]

10. Wu, Q.; Niu, F. Permafrost changes and engineering stability in Qinghai-Xizang Plateau. Chin. Sci. Bull. 2013, 58, 1079-1094. [CrossRef]

11. Zheng, B.; Zhang, J.; Qin, Y. Investigation for the deformation of embankment underlain by warm and ice-rich permafrost. Cold Reg. Sci. Technol. 2010, 60, 161-168. [CrossRef]

12. Tai, B.; Wu, Q.; Zhang, Z.; Xu, X. Cooling performance and deformation behavior of crushed-rock embankments on the Qinghai-Tibet Railway in permafrost regions. Eng. Geol. 2020, 265, 105453. [CrossRef]

13. Youhua, R.; Xin, L. Progress, Challenges and Opportunities of Permafrost Mapping in China. Adv. Earth Sci. 2019, 34, 1015-1027. (In Chinese)

14. Qin, Y.; Zhang, J.; Li, G.; Qu, G. Settlement characteristics of unprotected embankment along the Qinghai-Tibet Railway. Cold Reg. Sci. Technol. 2010, 60, 84-91. [CrossRef]

15. Chen, D.; Fu, Y.-S.; Cai, B.; Yuan, Y.-X. Modeling and algorithms of GPS data reduction for the Qinghai-Tibet railway. IEEE Trans. Intell. Transp. Syst. 2010, 11, 753-758. [CrossRef]

16. Niu, F.; Luo, J.; Lin, Z.; Liu, M.; Yin, G. Thaw-induced slope failures and susceptibility mapping in permafrost regions of the Qinghai-Tibet Engineering Corridor, China. Nat. Hazards 2014, 74, 1667-1682. [CrossRef]

17. Rouyet, L.; Lauknes, T.R.; Christiansen, H.H.; Strand, S.M.; Larsen, Y. Seasonal dynamics of a permafrost landscape, Adventdalen, Svalbard, investigated by InSAR. Remote Sens. Environ. 2019, 231, 111236. [CrossRef]

18. Zhang, Z.; Wang, M.; Wu, Z.; Liu, X. Permafrost deformation monitoring along the qinghai-tibet plateau engineering corridor using InSAR observations with multi-sensor SAR datasets from 1997-2018. Sensors 2019, 19, 5306. [CrossRef] [PubMed]

19. Daout, S.; Doin, M.P.; Peltzer, G.; Socquet, A.; Lasserre, C. Large-scale InSAR monitoring of permafrost freeze-thaw cycles on the Tibetan Plateau. Geophys. Res. Lett. 2017, 44, 901-909. [CrossRef]

20. Rudy, A.C.; Lamoureux, S.F.; Treitz, P.; Short, N.; Brisco, B. Seasonal and multi-year surface displacements measured by DInSAR in a High Arctic permafrost environment. Int. J. Appl. Earth Obs. Geoinf. 2018, 64, 51-61. [CrossRef]

21. Antonova, S.; Sudhaus, H.; Strozzi, T.; Zwieback, S.; Kääb, A.; Heim, B.; Langer, M.; Bornemann, N.; Boike, J. Thaw subsidence of a yedoma landscape in northern Siberia, measured in situ and estimated from TerraSAR-X interferometry. Remote Sens. 2018, 10, 494. [CrossRef]

22. Chang, L.; Hanssen, R.F. Detection of permafrost sensitivity of the Qinghai-Tibet railway using satellite radar interferometry. Int. J. Remote Sens. 2015, 36, 691-700. [CrossRef]

23. Chen, F.; Lin, H.; Zhou, W.; Hong, T.; Wang, G. Surface deformation detected by ALOS PALSAR small baseline SAR interferometry over permafrost environment of Beiluhe section, Tibet Plateau, China. Remote Sens. Environ. 2013, 138, 10-18. [CrossRef]

24. Zhang, X.; Zhang, H.; Wang, C.; Tang, Y.; Zhang, B.; Wu, F.; Wang, J.; Zhang, Z. Time-series InSAR monitoring of permafrost freeze-thaw seasonal displacement over Qinghai-Tibetan Plateau using Sentinel-1 data. Remote Sens. 2019, 11, 1000. [CrossRef]

25. Zebker, H.A.; Villasenor, J. Decorrelation in interferometric radar echoes. IEEE Trans. Geosci. Remote Sens. 1992, 30, 950-959. [CrossRef] 
26. Beck, I.; Ludwig, R.; Bernier, M.; Strozzi, T.; Boike, J. Vertical movements of frost mounds in subarctic permafrost regions analyzed using geodetic survey and satellite interferometry. Earth Surf. Dyn. 2015, 3, 409-421. [CrossRef]

27. Wang, L.; Marzahn, P.; Bernier, M.; Jacome, A.; Poulin, J.; Ludwig, R. Comparison of TerraSAR-X and ALOS PALSAR differential interferometry with multisource DEMs for monitoring ground displacement in a discontinuous permafrost region. IEEE J. Sel. Top. Appl. Earth Obs. Remote Sens. 2017, 10, 4074-4093. [CrossRef]

28. Chen, F.; Lin, H.; Li, Z.; Chen, Q.; Zhou, J. Interaction between permafrost and infrastructure along the Qinghai-Tibet Railway detected via jointly analysis of C-and L-band small baseline SAR interferometry. Remote Sens. Environ. 2012, 123, 532-540. [CrossRef]

29. Wang, L.; Marzahn, P.; Bernier, M.; Ludwig, R. Sentinel-1 InSAR measurements of deformation over discontinuous permafrost terrain, Northern Quebec, Canada. Remote Sens. Environ. 2020, 248, 111965. [CrossRef]

30. Ferretti, A.; Prati, C.; Rocca, F. Permanent scatterers in SAR interferometry. IEEE Trans. Geosci. Remote Sens. 2001, 39, 8-20. [CrossRef]

31. Chen, J.; Liu, L.; Zhang, T.; Cao, B.; Lin, H. Using persistent scatterer interferometry to map and quantify permafrost thaw subsidence: A case study of Eboling Mountain on the Qinghai-Tibet Plateau. J. Geophys. Res. Earth Surf. 2018, 123, 2663-2676. [CrossRef]

32. Berardino, P.; Fornaro, G.; Lanari, R.; Sansosti, E. A new algorithm for surface deformation monitoring based on small baseline differential SAR interferograms. IEEE Trans. Geosci. Remote Sens. 2002, 40, 2375-2383. [CrossRef]

33. Wang, J.; Wang, C.; Zhang, H.; Tang, Y.; Zhang, X.; Zhang, Z. Small-Baseline Approach for Monitoring the Freezing and Thawing Deformation of Permafrost on the Beiluhe Basin, Tibetan Plateau Using TerraSAR-X and Sentinel-1 Data. Sensors 2020, $20,4464$. [CrossRef]

34. Li, Z.; Zhao, R.; Hu, J.; Wen, L.; Feng, G.; Zhang, Z.; Wang, Q. InSAR analysis of surface deformation over permafrost to estimate active layer thickness based on one-dimensional heat transfer model of soils. Sci. Rep. 2015, 5, 1-9.

35. Jia, Y.; Kim, J.-W.; Shum, C.; Lu, Z.; Ding, X.; Zhang, L.; Erkan, K.; Kuo, C.-Y.; Shang, K.; Tseng, K.-H. Characterization of active layer thickening rate over the northern Qinghai-Tibetan plateau permafrost region using ALOS interferometric synthetic aperture radar data, 2007-2009. Remote Sens. 2017, 9, 84. [CrossRef]

36. Liu, L.; Zhang, T.; Wahr, J. InSAR measurements of surface deformation over permafrost on the North Slope of Alaska. J. Geophys. Res. Earth Surf. 2010, 115, F3. [CrossRef]

37. Liu, L.; Schaefer, K.; Zhang, T.; Wahr, J. Estimating 1992-2000 average active layer thickness on the Alaskan North Slope from remotely sensed surface subsidence. J. Geophys. Res. Earth Surf. 2012, 117, F1. [CrossRef]

38. Zhao, R.; Li, Z.-W.; Feng, G.-C.; Wang, Q.-J.; Hu, J. Monitoring surface deformation over permafrost with an improved SBASInSAR algorithm: With emphasis on climatic factors modeling. Remote Sens. Environ. 2016, 184, 276-287. [CrossRef]

39. Zhang, Z.; Wang, M.; Liu, X.; Wang, C.; Zhang, H. Map and Quantify the Ground Deformation Around Salt Lake in Hoh Xil, Qinghai-Tibet Plateau Using Time-Series InSAR From 2006 to 2018. IEEE J. Sel. Top. Appl. Earth Obs. Remote Sens. 2020, 14, 858-869. [CrossRef]

40. Wang, C.; Zhang, Z.; Zhang, H.; Wu, Q.; Zhang, B.; Tang, Y. Seasonal deformation features on Qinghai-Tibet railway observed using time-series InSAR technique with high-resolution TerraSAR-X images. Remote Sens. Lett. 2017, 8, 1-10. [CrossRef]

41. Wang, C.; Zhang, Z.; Zhang, H.; Zhang, B.; Tang, Y.; Wu, Q. Active layer thickness retrieval of Qinghai-Tibet permafrost using the TerraSAR-X InSAR technique. IEEE J. Sel. Top. Appl. Earth Obs. Remote Sens. 2018, 11, 4403-4413. [CrossRef]

42. Zhang, X.; Zhang, H.; Wang, C.; Tang, Y.; Zhang, B.; Wu, F.; Wang, J.; Zhang, Z. Active Layer Thickness Retrieval Over the Qinghai-Tibet Plateau Using Sentinel-1 Multitemporal InSAR Monitored Permafrost Subsidence and Temporal-Spatial Multilayer Soil Moisture Data. IEEE Access 2020, 8, 84336-84351. [CrossRef]

43. Chen, J.; Wu, Y.; O'Connor, M.; Cardenas, M.B.; Schaefer, K.; Michaelides, R.; Kling, G. Active layer freeze-thaw and water storage dynamics in permafrost environments inferred from InSAR. Remote Sens. Environ. 2020, 248, 112007. [CrossRef]

44. Daout, S.; Dini, B.; Haeberli, W.; Doin, M.-P.; Parsons, B. Ice loss in the Northeastern Tibetan Plateau permafrost as seen by 16 yr of ESA SAR missions. Earth Planet. Sci. Lett. 2020, 545, 116404. [CrossRef]

45. Lu, P.; Han, J.; Li, Z.; Xu, R.; Li, R.; Hao, T.; Qiao, G. Lake outburst accelerated permafrost degradation on Qinghai-Tibet Plateau. Remote Sens. Environ. 2020, 249, 112011. [CrossRef]

46. Zhang, Q.; Li, Y.; Zhang, J.; Luo, Y. InSAR technique applied to the monitoring of the Qinghai-Tibet Railway. Nat. Hazards Earth Syst. Sci. 2019, 19, 2229-2240. [CrossRef]

47. Han, J.; Lu, P. Retrieving Surface Deformation of the Qinghai-Tibet Railway Across Permafrost Areas from InSAR. In Proceedings of the IGARSS 2020-2020 IEEE International Geoscience and Remote Sensing Symposium, Waikoloa, HI, USA, 26 September-2 October 2020; pp. 3074-3077.

48. Youwu, Z.; Dongxin, G. Principal characteristics of permafrost in China. J. Glaciol. Geocryol. 1982, 4, 1-19.

49. Li, X.; Cheng, G. A GIS-aided response model of high-altitude permafrost to global change. Sci. China Ser. D Earth Sci. 1999, 42, 72-79. [CrossRef]

50. Qiu, G. The principle of geocryological regionalization and the compilation of frozen ground map. In Geocryology in China; Zhou, Y.W., Guo, D.X., Qiu, G.Q., Cheng, G.D., Li, S.D., Eds.; Science Press: Beijing, China, 2000; pp. 162-170.

51. Wang, T.; Wang, N.; Li, S. Map of the Glaciers, Frozen Ground and Desert in China, 1:4,000,000; Chinese Map Press: Beijing, China, 2006. 
52. Ran, Y.; Li, X.; Cheng, G.; Zhang, T.; Wu, Q.; Jin, H.; Jin, R. Distribution of permafrost in China: An overview of existing permafrost maps. Permafr. Periglac. Process. 2012, 23, 322-333. [CrossRef]

53. Zou, D.; Zhao, L.; Sheng, Y.; Chen, J.; Hu, G.; Wu, T.; Wu, J.; Xie, C.; Wu, X.; Pang, Q. A new map of permafrost distribution on the Tibetan Plateau. Cryosphere 2017, 11, 2527-2542. [CrossRef]

54. Ran, Y.; Li, X.; Cheng, G. Climate warming over the past half century has led to thermal degradation of permafrost on the Qinghai-Tibet Plateau. Cryosphere 2018, 12, 595-608. [CrossRef]

55. Wu, Q.; Zhang, T. Changes in active layer thickness over the Qinghai-Tibetan Plateau from 1995 to 2007. J. Geophys. Res. Atmos. 2010, 115, 115. [CrossRef]

56. Xi, X.; Xu, Z. Ecological environment protection in the construction of Qinghai-Tibet railway. Environ. Sci Technol. 2005, 28, $119-121$.

57. Chen, D.; Cheng, R. Intelligent Processing Algorithms and Applications for GPS Positioning Data of Qinghai-Tibet Railway; Springer: Berlin/Heidelberg, Germany, 2019.

58. Wu, Q.; Zhang, T.; Liu, Y. Thermal state of the active layer and permafrost along the Qinghai-Xizang (Tibet) Railway from 2006 to 2010. Cryosphere 2012, 6, 607-612. [CrossRef]

59. Wu, Q.; Cheng, G.; Ma, W.; Niu, F.; Sun, Z. Technical approaches on permafrost thermal stability for Qinghai-Tibet Railway. Geomech. Geoengin. Int. J. 2006, 1, 119-127. [CrossRef]

60. Ni, J.; Wu, T.; Zhu, X.; Wu, X.; Pang, Q.; Zou, D.; Chen, J.; Li, R.; Hu, G.; Du, Y. Risk assessment of potential thaw settlement hazard in the permafrost regions of Qinghai-Tibet Plateau. Sci. Total Environ. 2021, 776, 145855. [CrossRef]

61. Savitzky, A.; Golay, M.J. Smoothing and differentiation of data by simplified least squares procedures. Anal. Chem. 1964, 36, 1627-1639. [CrossRef]

62. Memarsadeghi, N.; Mount, D.M.; Netanyahu, N.S.; Le Moigne, J. A fast implementation of the ISODATA clustering algorithm. Int. J. Comput. Geom. Appl. 2007, 17, 71-103. [CrossRef]

63. Xu, X.; Sandwell, D.T.; Tymofyeyeva, E.; González-Ortega, A.; Tong, X. Tectonic and anthropogenic deformation at the Cerro Prieto geothermal step-over revealed by Sentinel-1A InSAR. IEEE Trans. Geosci. Remote Sens. 2017, 55, 5284-5292. [CrossRef]

64. Agram, P.; Jolivet, R.; Riel, B.; Lin, Y.; Simons, M.; Hetland, E.; Doin, M.P.; Lasserre, C. New radar interferometric time series analysis toolbox released. EOS Trans. Am. Geophys. Union 2013, 94, 69-70. [CrossRef]

65. Hu, Y.; Liu, L.; Larson, K.M.; Schaefer, K.M.; Zhang, J.; Yao, Y. GPS interferometric reflectometry reveals cyclic elevation changes in thaw and freezing seasons in a permafrost area (Barrow, Alaska). Geophys. Res. Lett. 2018, 45, 5581-5589. [CrossRef]

66. Cao, B.; Zhang, T.; Peng, X.; Mu, C.; Wang, Q.; Zheng, L.; Wang, K.; Zhong, X. Thermal characteristics and recent changes of permafrost in the upper reaches of the heihe river basin, Western China. J. Geophys. Res. Atmos. 2018, 123, 7935-7949. [CrossRef]

67. López-Quiroz, P.; Doin, M.-P.; Tupin, F.; Briole, P.; Nicolas, J.-M. Time series analysis of Mexico City subsidence constrained by radar interferometry. J. Appl. Geophys. 2009, 69, 1-15. [CrossRef]

68. Wang, C.; Tang, Y.; Zhang, H.; You, H.; Zhang, W.; Duan, W.; Wang, J.; Dong, L.; Zhang, B. First mapping of China surface movement using supercomputing interferometric SAR technique. Sci. Bull. 2021, 66, 1608-1610. [CrossRef]

69. Zhou, C.; Gong, H.; Chen, B.; Gao, M.; Cao, Q.; Cao, J.; Duan, L.; Zuo, J.; Shi, M. Land subsidence response to different land use types and water resource utilization in Beijing-Tianjin-Hebei, China. Remote Sens. 2020, 12, 457. [CrossRef]

70. Dik, A.; El Moujahid, A.; Jebari, K.; Ettouhami, A. A new dynamic algorithm for unsupervised learning. Int. J. Innov. Comput. Inf. Control. 2015, 11, 1325-1339.

71. Ball, G.H.; Hall, D.J. ISODATA, A Novel Method of Data Analysis and Pattern Classification; Stanford Research Institute: Menlo Park, CA, USA, 1965.

72. ERA Monthly Averaged Data on Pressure Levels from 1979 to Present. Available online: https://cds.climate.copernicus.eu/ cdsapp\#!/dataset/10.24381/cds.6860a573?tab=overview (accessed on 20 October 2021).

73. Yao, X.; Sun, M.; Gong, P.; Liu, B.; Li, X.; An, L.; Yan, L. Overflow probability of the salt lake in Hoh Xil region. J. Geogr. Sci. 2018, 28, 647-655. [CrossRef]

74. Zhou, H.; Zhao, L.; Tian, L.; Wu, Z.; Xie, M.; Yuan, L.; Ni, J.; Qiao, Y.; Gao, Z.; Shi, J. Monitoring and analysis of surface deformation in the permafrost area of Wudaoliang on the Tibetan Plateau based on Sentinel-1 data. J. Glaciol. Geocryol. 2019, 41, 525-536. (In Chinese)

75. Zhao, L. A New Map of Permafrost Distribution on the Tibetan Plateau (2017); National Tibetan Plateau Data Center: Beijing, China, 2019. [CrossRef]

76. Hong, Z.; Jin, S. Permafrost deformation in Qinghai-Tibet Plateau time-series PS-InSAR. Bull. Surv. Mapp. 2021, 1, 35-40. (In Chinese) [CrossRef]

77. Zhao, T.; Zhang, M.; Lu, J.; Yan, Z. Correlation between the ground surface deformation and influential factors in permafrost regions. J. Harbin Inst. Technol. 2021, 53, 145-153. (In Chinese) [CrossRef]

78. Li, R.; Li, Z.; Han, J.; Lu, P.; Qiao, G.; Meng, X.; Hao, T.; Zhou, F. Monitoring surface deformation of permafrost in Wudaoliang Region, Qinghai-Tibet Plateau with ENVISAT ASAR data. Int. J. Appl. Earth Obs. Geoinf. 2021, 104, 102527. [CrossRef] 